TRABAJOS DE PREHISTORIA

$51, \mathrm{n} .^{\circ} 1,1994$, pp. $15-37$

\section{DINÁMICA TRÓFICA, ESTRATEGIAS DE CONSUMO Y ALTERACIONES ÓSEAS EN LA SABANA AFRICANA: RESUMEN DE UN PROYECTO DE INVESTIGACIÓN ETOARQUEOLÓGICO (1991-1993)}

\author{
TROPHIC DYNAMICS, CONSUMPTION \\ STRATEGIES AND BONE ALTERATIONS \\ IN THE AFRICAN SAVANNA \\ ECOSYSTEM: SUMMARY \\ OF AN ETHO-ARCHAEOLOGICAL \\ RESEARCH PROJECT (1991-1993)
}

MANUEL DOMÍNGUEZ- RODRIGO (*)

\section{RESUMEN}

Se exponen los principales resultados de un amplio proyecto de investigación etoarqueológica llevado a cabo en Africa oriental. Estos sirven de base para la interpretación del comportamiento de los predadores de sabana y estepa, con respecto al proceso de consumo de sus presas, creando al mismo tiempo un marco referencial de gran utilidad para la Tafonomía. El comportamiento de los carnívoros se explica en términos de su variabilidad contextual, debida a la modificación de la presión selectiva según la dinámica trófica. Por consiguiente, se discuten los principales patrones adaptativos de estos predadores y se pone especial énfasis en el papel jugado por la ecología en la conducta que exhibe cada uno de ellos. Las principales cuestiones tratadas son las estrategias iniciales de consumo, los agentes y contextos que generan acumulaciones óseas, el espectro cinegético de cada carnívoro y los patrones de alteración ósea. Como complemento innovador a estos temas, se

(*) Departamento de Prehistoria. Facultad de Geografía e Historia. Universidad Complutense. 28040 Madrid.

$\mathrm{El}$ artículo fue remitido en su versión final el 21-I-94. presenta también el análisis espacial de dispersión de restos debido a la acción de los predadores en la desarticulación y consumo de carcasas.

\footnotetext{
ABSTRACT

The main results of a broad etho-archaeological research carried out in East Africa are succintly exposed. These provide an accurate explanation of the behavior exhibited by the main savanna and steppe predators with regard to the process of carcass consumption, thereby cre. ating a referential framework that can be useful for taphonomists. Carnivore behavior is accounted for in terms of its contextual variability, due to the changing selective pressure according to trophic dynamics. Therefore, the adaptive patterns of each predator are discussed and special emphasis is laid on the role played by ecology in shaping their behavior. Initial consumption strategies, bone accumulating agencies and contexts, the predatory range of each predator and bone modification patterns are the main subjects treated. As an innovative complement to these issues, the spatial analysis of bone dispersal by carcass proccessing is introduced.
} 
Palabras clave: Etoarqueologia. Dinámica trófica. Presión selectiva. Predador. Alteración ósea. Análisis espacial.

Key words: Etho-archaeology. Trophic dynamics. Selective pressure. Predator. Bone modification. Spatial analysis.

\section{INTRODUCCIÓN}

Cuestiones esenciales de la evolución de nuestra conducta dependen de una correcta interpretación tafonómica del registro arqueológico. ¿Fue el ser humano el único responsable del mismo? Si no lo fue ¿qué orden de intervención ocupó? ¿Consiguió lo que allí aportó mediante caza o carroñeo? ¿Compartió el alimento con otros miembros de su grupo? ¿Cómo se distorsionó dicho registro tras su abandono por los homínidos? Para disponer de la información que cada yacimiento contiene al respecto es imprescindible someterlo al tamiz de la Tafonomía, el cual nos informa de la presencia/ausencia de elementos óseos y su estado de alteración. Pero una vez realizado este procedimiento, es necesario hacer inteligibles los datos obtenidos, dentro de un marco referencial en el que la Etología resulta esencial. No podemos responder a ninguna de las preguntas formuladas si no conocemos el comportamiento de las distintas especies carnívoras en cada tipo de ecosistema y hábitat para saber qué cazan, qué productos dejan disponibles para ser aprovechados de modo secundario, cómo y quienes realizan un consumo terminal de ciertos restos, y por tanto distorsionan el patrón deposicional generado por otros agentes, procesos de desplazamiento y/o amontonamiento de huesos, etc... De este modo, el estudio etológico orientado arqueológicamente resulta imprescindible para el Paleolítico y es también de gran utilidad para periodos posteriores en los que la inteligibilidad de los restos plantea menos problemas.

Esta necesidad de conocer los procesos biológicos que operan sobre los restos óseos, para poder interpretar las acumulaciones de huesos que forman parte del registro arqueológico plio-pleistocénico, ha provocado el estudio de dichos procesos de manera especial durante las últimas dos décadas. A partir de semejantes investigaciones, se han elaborado marcos referen- ciales que, a la vez que han servido para interpretar, han impulsado el desarrollo e implantación de diversas técnicas analíticas tafonómicas. Sin embargo, la parte clásica de estos estudios que yo atribuiría a una primera fase en la investigación etoarqueológica-, adolece de serias carencias por diversas razones. En primer lugar, por haberse centrado en especies carnívoras concretas, dejando al margen a otras (Binford, 1981; Brain, 1981) -en la actualidad, no hay trabajos sobre el comportamiento de leones y otros félidos (como el tigre) o licaones, chacales y la mayor parte de cánidos, en procesos de alteración ósea elementales-. En segundo lugar, por haber elaborado diagnosis de alteración y acumulación de las especies estudiadas, a partir de conjuntos óseos ya formados (consideración estática), con lo que no se han controlado los factores que los han condicionado y, en algunos casos, su integridad. Esto es lo que sucede, por ejemplo, con las acumulaciones de huesos atribuidas a leopardos en contextos cársticos, estando todas posiblemente "contaminadas" por otros agentes (en especial el puercoespín) (Brain, 1981; Bunn, 1982). En tercer lugar, porque -debido a dicho enfoque estático- no se ha considerado la influencia de las condiciones del contexto ecológico en las conductas de los animales carnívoros y su margen de variación, con lo que este hecho repercute en la validez de las diagnosis elaboradas (Binford, 1981; Brain, 1981). Y en cuarto y último lugar, porque se han sobrevalorado en algunos casos determinados tipos de análisis sobre otros, que en la actualidad o bien pueden refinarse con otros enfoques y métodos de investigación o bien se han transformado.

Una segunda fase en la investigación etoarqueológica -que corrige la mayor parte de estas carencias- podría situarse en la segunda mitad de la década de los ochenta, en la que los objetos de estudio se amplían. El estudio de los agentes biológicos que acumulan huesos y sus formas de modificarlos ya no son el propósito central, sino que se investiga también otra serie de cuestiones; por ejemplo, la disponibilidad de carcasas en determinados medios y su acceso a través de estrategias oportunistas (Blumenschine, 1986), los procesos de muertes naturales en masa (con nuevas consideraciones) y los lugares preferenciales de acumulación ósea por efecto de predación en serie (Haynes, 1988a, 1988 b), etc... Estas investigaciones y otras son 
posibles debido a que se considera ahora al contexto ecológico desde su propia variabilidad física y temporal, y se analizan procesos activos de formación (consideración dinámica) (Blumenschine \& Marean, 1993). Por ello surgen estudios sobre los tipos de huesos y su dispersión en distintos tipos de hábitats según la presión trófica (Blumenschine, 1989), sobre los modos de alteración diferencial de conjuntos óseos según el acceso primario/secundario a los mismos de los carnívoros (Blumenschine, 1988), y su distorsión tafonómica (Capaldo, 1990; Marean et alii, 1992), sobre procesos excepcionales de aprovechamiento de carcasas (Cavallo \& Blumenschine, 1989), la variación de la presión trófica y el establecimiento de enclaves de ocupación prolongada (Cavallo, 1993), etc...

Dentro de esta línea de investigación se encuadra el presente trabajo, que pretende ser un resumen sucinto de un proyecto de investigación etoarqueológica que he realizado desde 1991 hasta 1993, en tres campañas sucesivas a lo largo de épocas distintas del año (Marzo-Abril, Julio-Agosto), en diversos parques y reservas naturales -y en sus áreas periféricas, que incluyo dentro de cada uno de ellos- de Kenia y Tanzania. Estos han sido, por lo que concierne a este artículo y dependiendo del tipo de análisis, los siguientes: Masai Mara, Amboseli, Nakuru y Sibiloit en Kenia, y Serengeti en Tanzania (Fig. 1). Estos parques y reservas fueron frecuentados con regularidad a lo largo de las tres campañas, salvo el Parque Natural de Sibiloit, que sólo fue visitado en la campaña Marzo-Abril de 1991. En ellos he realizado observaciones directas sobre los procesos de captación primaria de

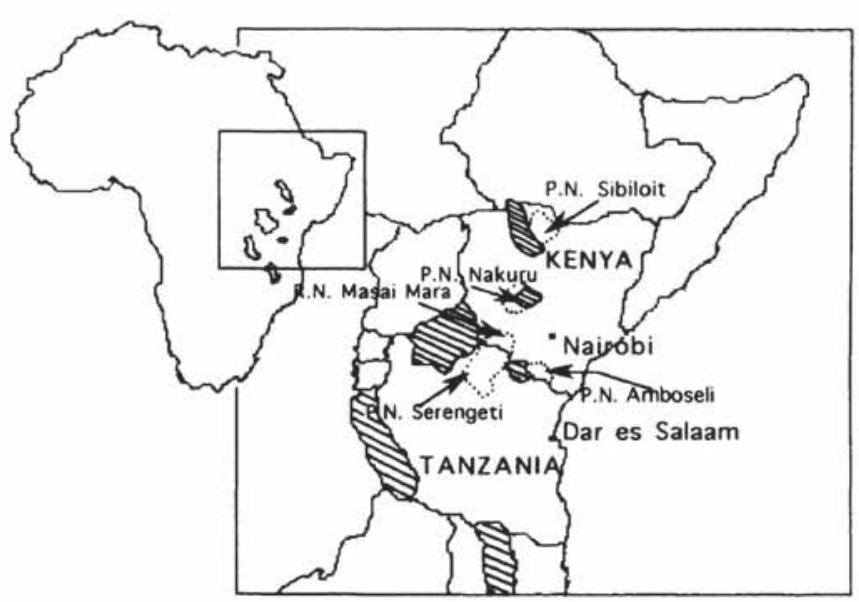

FIg. 1 Mapa general de Kenia y Tanzania y situación de los parques naturales citados en el texto. carcasas por parte de distintas especies carnívoras (fase 1), tanto mediante estrategias cinegéticas (caza) como oportunistas (carroñeo), y acceso a las mismas de modo secundario, tras otro carnívoro (fase 2). Dichas observaciones se llevaron a cabo a lo largo de diversas horas del día, y las realizadas en el Parque Natural del Serengeti también durante la noche a lo largo de 20 días. En dicho trabajo pretendo tratar, a modo de resumen, los factores que intervienen en la movilización de restos y sus procesos de acumulación, y el estudio del espectro cinegético y de las formas de alteración ósea de los principales carnívoros de los ecosistemas africanos de sabana y estepa. Con ello quiero no sólo realizar un trabajo de síntesis -obligado por la dificultad de publicar trabajos de este tipo con una orientación más concreta-, sino presentar información nueva. Mi aportación más relevante, en este sentido, pretende ser el tratamiento etoarqueológico de la conducta del león, de la que hasta ahora poseía escasa información, y la presentación del análisis espacial de tipo micro aplicado a estas cuestiones, orientado evidentemente hacia el área tafonómica. Para ello, he extraído información de un total de 39 asociaciones óseas generadas por acciones cinegéticas atribuidas a leones (24), guepardos (9) y leopardos (6).

\section{LA ETOARQUEOLOGÍA COMO DISCIPLINA COMPLEMENTARIA DE LA TAFONOMÍA}

Todo dato que un tafónomo obtiene a partir de sus análisis necesita hacerlo inteligible dentro de un marco referencial determinado. Los estudios de los índices de representación esquelética, los perfiles de edad, la variedad taxonómica y los patrones de alteración ósea, por ejemplo, se realizan en función del referente de que ciertos procesos biológicos producen en la actualidad diagnosis concretas que sirven para discriminar a los agentes responsables. Sin embargo, sería un error considerar que la elaboración de dicho marco de referencia es parte integral de la disciplina tafonómica, dentro de su línea habitual de investigación. Aunque análisis e interpretación se encuentran intrínsecamente relacionados por ser parte consustancial del mismo proceso inferencial, podría establecerse una distinción entre ambos en el seno de la Ta- 
fonomia, basada en que la parte analítica consiste -partiendo de un posicionamiento teórico previo- en el uso de métodos y técnicas de escrutinio, utilizados en una acumulación ósea con la finalidad de obtener una serie de datos, y la parte interpretativa, en el empleo de dichos datos para elaborar una explicación, basada en un conocimiento referencial anterior. Considero, por consiguiente, que la creación de semejante marco de interpretación debe entenderse, pese a su innegable relación con la Tafonomía, como una disciplina propia. La denominación que le corresponde es la de "Etoarqueología", puesto que si al estudio de los procesos generadores de un registro material realizado con etnias humanas modernas se le denomina "Etnoarqueología" -Etnología aplicada a nuestra disciplina-, el análisis de los mismos con otros agentes biológicos deberá hacerse desde la Etología -igualmente aplicada a la Arqueología-. En ambos casos lo que se está haciendo es desarrollar la "teoría de alcance medio" (Binford, 1981), con el fin de ampliar y mejorar el marco interpretativo al que deben someterse los análisis tafonómicos y arqueológicos.

Los principales argumentos que se pueden utilizar para diferenciar a la Etoarqueología de la Tafonomía son que la primera se ocupa del estudio de procesos dinámicos cuyas causas y efectos son observables, es susceptible de experimentación, ya que pueden controlarse distintas variables, y el objeto de análisis es la variedad de resultados materiales de los comportamientos animales no antrópicos en sus contextos ecológicos. El principal objetivo es, pues, ver cómo determinadas conductas (causas) producen resultados definidos (efectos). La Tafonomía, en cambio, necesita hacer comprensibles tafocenosis, o lo que es igual, analizar acumulaciones óseas fósiles (efectos) para poder estar en disposición de averiguar su proceso de formación (causas). El modo de actuación es, por consiguiente, inverso. Por ello, se ocupa de secuencias estáticas, como son las tafocenosis, y no de procesos dinámicos, con lo que no sólo se desconocen de antemano las causas, sino que tampoco se puede acceder a las variables que condicionaron las conductas responsables de la formación de dichas acumulaciones óseas. Para explicarlas, la Tafonomía necesita de la Etoarqueología -que la provee de marcos de referencia-, la cual a su vez es una disciplina autosuficiente, que no sólo debe dedicarse a la des- cripción de conductas, sino a su explicación dentro de una dinámica ecológica contextual.

Otra de las razones que apuntalan la diferenciación entre ambas disciplinas es la amplitud de campos, técnicas y objetos de estudio, que pueden resultar difícilmente abarcables desde una sola disciplina. La principal carencia de la mayor parte de tafónomos es su escasa formación etológica, la cual les incapacita en muchos casos para interpretar los registros óseos que ellos mismos han analizado. Semejante afirmación no debiera interpretarse como un reproche gratuito, puesto que esta situación no es sino el resultado de que la Tafonomía -entendida en su aspecto analítico- ya es de por sí lo suficientemente amplia como para que requiera la participación conjunta de varios especialistas. La figura del supertafónomo capacitado para realizar por sí solo cualquier tipo de análisis es irreal. Si el tafónomo debe ser, dentro de la línea analítica, un especialista, no se le puede exigir que conozca en profundidad todos los procesos biológicos que se relacionan con las acumulaciones y alteraciones óseas, sólo accesibles a través de la Etología. Estos, por otra parte, aún centrándose en la Etología de carnívoros, son tan amplios y dependen de variables tan diversas, que precisan de un esfuerzo que sólo se puede dispensar desde una disciplina a parte, como es el caso de la Etoarqueología.

Podría utilizarse del mismo modo, como argumento complementario a esta separación, la distinta procedencia de los enfoques que pueden amparar a una y otra disciplina. Mientras que la Etoarqueología se basa en la Etología -estudio del comportamiento de los animales-, la Tafonomía, entendida en su vertiente analítica, se fundamenta en la Zoología -de ahí la denominación Zooarqueología-, centrada más en el análisis físico de los mismos. Otra manera de entender esta situación sería distinguir entre la Zooarqueología -como análisis del registro óseo- y la Etoarqueología -como interpretación del mismo-, dentro de un concepto de la Tafonomía más amplio, que abarcase en este caso ambas "subdisciplinas" y cumpliese su objetivo: analizar e interpretar palimpsestos.

Otorgándole, pues, un valor disciplinar, la Etoarqueología no sólo se ocupa del estudio del comportamiento de las especies carnívoras, como podría parecer más relevante para cumplir los fines tafonómicos expuestos, sino que incluye también en su área de investigación a 
las especies herbívoras y sus procesos de adaptación y migración, para el estudio de procesos de muerte natural, catastrófica, etc... Igualmente, su área de interés va más allá del estrictamente tafonómico. La experimentación con chimpancés para evaluar capacidades y modos de talla de artefactos líticos (Toth \& Schick, 1993), o los patrones de acumulación de restos en la reincidencia de la ocupación de determinados enclaves por parte de estos primates, también se encuadran dentro de la denominación "investigación etoarqueológica" (Sept, 1992).

El trabajo que presento a continuación, de clara orientación tafonómica, se basa en la utilización de distintas variables ecológicas para observar la variación de los procesos modificadores de las carcasas animales. Algunos estudios anteriores, de indudable valor en esta disciplina, como los de Binford (1981) o Brain (1981), adolecen de una falta de consideración de las condiciones del contexto ecológico, las cuales influyen de manera determinante en cada uno de los tipos de conducta.

\section{ESTRATEGIAS INICIALES DE CONSUMO: TIPOS Y CAUSAS DEL DESPLAZAMIENTO DE PRESAS}

El modo en que una carcasa va a ser alterada en su proceso de desarticulación y aprovechamiento depende en primera instancia de la estrategia de consumo adoptada por el(los) predador(es) que interviene(n) en la misma en su acceso primario. La movilización de un animal capturado siempre supone un desgaste energético que sólo se rentabiliza en función de la disminución del riesgo de ser arrebatado por otro competidor. Por esta razón, el consumo de una presa en el lugar de captura o su desplazamiento a otro sitio son dos opciones que responden a una misma estrategia subsistencial: la minimización del gasto energético y su consiguiente optimización.

El factor principal que condiciona semejante comportamiento es la posición que el animal carnívoro ocupa dentro de la dinámica trófica; es decir, su capacidad de retención de la presa y de disuasión frente a otros competidores. Cuanto más elevada es dicha posición, menor es la probabilidad de que la presa sea desplazada. Cuando se ocupa un puesto intermedio o bajo y es necesario un desplazamiento de la misma, éste suele ser radial y reducido, debido al criterio aludido de optimización de la energía invertida, ya que los traslados largos exigen un mayor desgaste e incrementan las probabilidades de encuentro con otros animales carnívoros. Los factores que determinan la posición trófica de un predador son su dotación física y el tipo de organización social que mantiene. Un predador grande posee una mayor capacidad de protección de su presa que uno pequeño, y aquéllos que se organizan en grupos gregarios son más "fuertes" que los solitarios. Tanto es así, que el tipo de relación social suele ser más importante que las características físicas. Sirva como ejemplo el hecho de que las hienas y licaones (animales gregarios) pueden arrebatar la presa a un leopardo (animal solitario), pese a su mayor tamaño, al igual que sucede en el caso de los cuones (perros salvajes asiáticos) con respecto al tigre. En dicho orden trófico, en la sabana y estepa africanas, el león (grande y gregario) ocupa una posición alta, hienas y licaones (de tamaño mediano, pero gregarios) se sitúan en un escalafón intermedio, seguidos en inferioridad de condiciones por el leopardo y el guepardo (de tamaño mediano y solitarios), y en un puesto más bajo se encuentran chacales y zorros (pequeños y poco gregarios).

Siguiendo el mismo orden de importancia, el segundo factor que interviene en el acto de consumo in situ de la presa o su desplazamiento es el tipo de hábitat y sus condiciones ecológicas y físicas. En el ecosistema de sabana existen hábitats donde la presión trófica es elevada, debido al número y variedad de predadores -por ejemplo, las llanuras despejadas, que es donde se concentra la mayor parte de la biomasa herbívora-, y en donde algunos carnívoros de posición intermedia necesitan desplazar la presa, para consumirla, a lugares de menor riesgo. Sin embargo, en otros hábitats -como los bosques aluviales-, la escasa presencia de predadores facilita más el consumo in situ de las presas y propicia menos desplazamientos. Igualmente, la disposición o no de rasgos físicos del paisaje -árboles, arbustos, zonas de gramíneas altas, etc...influye en la existencia o ausencia de traslados y el alcance de los mismos.

Un tercer factor que condiciona el tipo de estrategia inicial de consumo de presas es el grado de disponibilidad estacional de recursos. En determinadas zonas, la concentración y dis- 
persión cíclica de fauna herbívora -generalmente coincidente con periodos migratoriosprovoca que en ciertas épocas del año exista una abundancia de alimento lo suficientemente importante como para reducir el número de desplazamientos de presas o restos, aún tratándose de especies carnívoras de posición intermedia, residentes en hábitats en los que el resto del año existe una presión trófica elevada.

Teniendo en cuenta los criterios biológico -tipo de carnívoro y su modo de organización social-, ecológico -tipo de medio y sus características tróficas- y temporal -ciertas épocas del año-, se puede entender mejor el comportamiento subsistencial de los predadores con respecto a la estrategia inicial empleada en el modo de aprovechamiento de sus presas. Existe, no obstante, un elemento de juicio que debe añadirse a estos factores expuestos, ya que resulta de vital importancia para comprender la forma en que se realiza -cuando esto ocurre- el traslado de la presa. El tipo de interacción social de una especie carnívora condiciona no sólo su posición en la escala trófica, sino también su manera de intervención y desplazamiento de una carcasa. Todos los predadores gregarios mantienen una cohesión social de grupo, coordinada por uno o varios individuos jerarcas. Esto propicia la cooperación de los miembros de un mismo grupo en la captura de presas. Sin embargo, tras su obtención, lo que interviene es lo que yo he denominado criterio de maximización individual de la ingesta de alimento, según el cual -en términos selectivos darvinistas-, lo que se impone es que cada individuo optimice al máximo su inversión energética compitiendo con sus propios compañeros por los recursos obtenidos de manera colectiva. Esto provoca que, mientras que los cazadores solitarios pueden desplazar sus presas intactas, los cazadores gregarios que efectúan algún traslado, lo hacen siempre tras un acto de consumo inicial, en el que se ha desarticulado la presa, y lo llevan a cabo a partir de determinados restos de la misma (Domínguez-Rodrigo, en prensa a). Uno de los ejemplos más ilustrativos de la importancia del tipo de interacción social es el caso del guepardo. Este félido suele vivir solo -incluyendo en este concepto a la hembra con sus crías, en el periodo reproductor- en un $60 \%$ de su población. El resto lo constituyen agrupaciones de dos o tres machos que forman estructuras pseudo-gregarias, que condicionan la estrategia inicial de

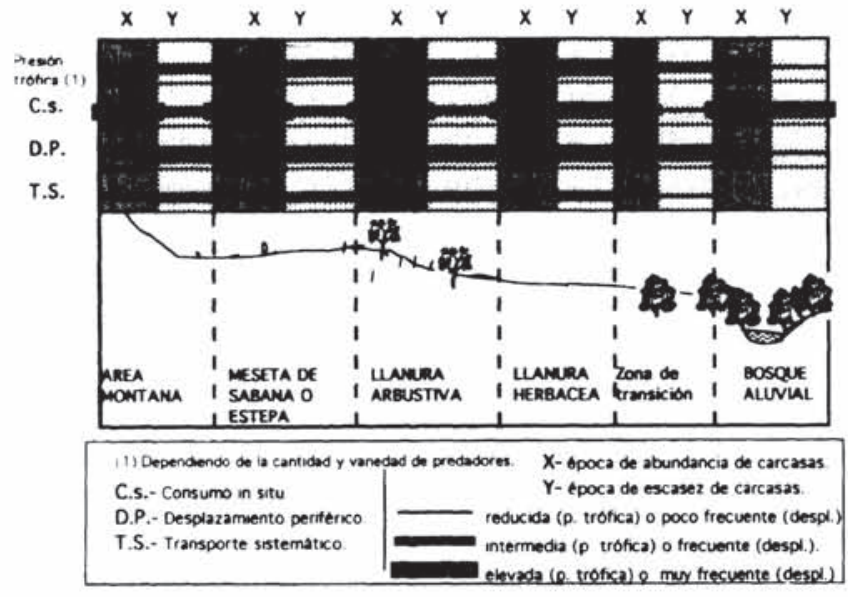

FIG. 2. Estrategias iniciales de consumo en los predadores de sabana y estepa, según el tipo de hábitat, y su relación con la presión trófica.

consumo: mientras que es frecuente que los individuos solitarios desplacen ligeramente su presa, los que residen en este tipo de grupos las consumen in situ, debido a la competencia entre ellos mismos y a su mayor capacidad de protección de la pieza.

Tres son, pues, las modalidades adoptadas en la estrategia inicial de consumo de los predadores con respecto a sus presas: consumo in situ, desplazamiento periférico y transporte sistemático (Domínguez-Rodrigo, en prensa b) (Figs. 2 y 3 ).

Consumo in situ - Es la estrategia que supone un menor esfuerzo energético -sólo el de la aprehensión- y un mayor beneficio. Por ello es el comportamiento más común entre los carnívoros de sabana. Lo exhiben las especies que ocupan la posición trófica más elevada, como el león que, a la ventaja de ser el carnívoro más grande de este ecosistema, añade la particularidad de ser gregario. Esto le capacita para defender su presa en todo tipo de hábitat; con lo cual, se puede permitir la táctica de desplazar a las crías al lugar donde la ha abatido y no a la inversa, como es más frecuente en otros predadores.

También es la solución que adoptan otras especies de organización social gregaria, como son las hienas y licaones. En este caso, se debe a que opera en ellos el criterio de maximización individual del aprovechamiento de recursos, que les impulsa a devorar la presa en cuanto la capturan. La estrategia que utilizan es la capaci- 
dad de consumir grandes cantidades de carne en poco tiempo. Ambas especies pueden consumir una presa de $250 \mathrm{~kg}$. de peso en menos de una hora (Fox, 1975; Blumenschine, 1986; Ammann \& Ammann, 1989; Scott, 1991). Con ello no sólo se optimiza la ingesta de alimento de cada individuo con respecto a su compañero, sino que a nivel de grupo se reduce la probabilidad de perder la presa a favor de otros predadores. Como no se tiene la capacidad de retención de la carcasa durante mucho tiempo -debido a que no ocupan una posición trófica similar a la del león-, los licaones regurgitan parte de su contenido estomacal a sus crías posteriormente. Las hienas, en cambio -debido al mismo motivo-, muestran una estrategia mixta, en la que tras un consumo inicial, desplazan algunos restos posteriormente a sus madrigueras y a otros enclaves.

Determinadas épocas del año -aquéllas en las que existe abundancia de alimento- propician también que en ciertas zonas algunos carnívoros, como las hienas, no desplacen restos -ni siquiera los que carroñean-, y que no realicen aporte ninguno a sus madrigueras. Del mismo modo, en ciertos tipos de paisaje -algunos de ellos ligados también a la variación climática estacional-, predadores que desplazan con frecuencia sus presas de su lugar de obtención -como es el caso del guepardo en estepas o llanuras de hierba baja-, no lo hacen por no existir lugares apropiados o por no haber una presión trófica significativa -como ocurre con los leopardos que habitan los bosques aluviales densos-.

Desplazamiento periférico- Debido a la presión trófica, los predadores solitarios suelen desplazar sus presas de su lugar de captura a un enclave más seguro. Estos puntos naturales de apoyo son árboles, arbustos o secciones de las llanuras con gramíneas elevadas. Debido a que el traslado de la carcasa, suele ser un gasto energético -más elevado cuanto mayor es la distancia recorrida-, que incrementa el riesgo de encuentro con otro predador en función del recorrido -mayor cuanto más largo-, y puesto que árboles, arbustos y hierbas altas suelen resultar frecuentes en bastantes hábitats abiertos, lo normal es que el desplazamiento periférico de una presa no exceda un radio de $250 \mathrm{~m}$. y sea bastante menor en la mayor parte de las ocasiones. En caso de que no se disponga de alguno de estos puntos naturales de apoyo en un radio como el señalado, el predador -como he tenido la oportunidad de observar algunas veces entre guepardos- opta por consumir la presa in situ. En el ecosistema de sabana, los carnívoros que desplazan periféricamente sus presas con mayor asiduidad son el leopardo -que la traslada a los árboles- y el guepardo -que la desplaza a zonas de arbustos o hierbas altas-. En ambos casos se observa una estrategia divergente. Mientras que el leopardo al subir su presa a un árbol, la mantiene fuera del alcance de otros competidores, el guepardo sólo reduce momentáneamente dicha posibilidad, al esconderla tras las hierbas o un arbusto. Esto facilita que el leopardo consuma su presa lentamente -puede durarle más de un par de días- y que el guepardo, en cambio, la procese con suma celeridad -en poco más de media hora-.

Existen, no obstante, otros predadores que también pueden desplazar periféricamente sus presas. En los leones se puede observar este hecho de manera esporádica, cuando sólo uno o dos individuos cazan un animal. La amenaza por parte de un grupo de hienas o licaones es suficiente para que estos félidos trasladen su pieza a un lugar próximo de mayor resguardo. Del mismo modo, en determinados hábitats -como en las zonas abiertas de las estepas arbustivas-, el calor y la proximidad de arbustos provoca con frecuencia que las manadas de leones desplacen restos de sus presas a lugares con sombra; pero en este caso lo hacen tras un consumo inicial y con éstas ya desarticuladas.

Igualmente, las hienas pueden desplazar restos -nunca carcasas enteras- a otros lugares, con la finalidad de almacenarlos. Estos sitios suelen ser "despensas acuáticas", en las que éstos se mantienen a salvo de otros carnívoros, como son las charcas de las llanuras abiertas, las zonas empantanadas $\mathrm{y}$, con mucha menor frecuencia, márgenes de lagos y ríos.

Transporte sistemático- Es la estrategia más marginal -y generalmente secundaria, tras la adopción de cualquiera de las anteriores en primera instancia- de las empleadas por los predadores. Consiste en el aporte reiterado de carcasas o restos a un mismo lugar durante un periodo de tiempo variable. Puede realizarse a grandes distancias, por lo que excede los $250 \mathrm{~m}$. radiales del desplazamiento periférico. En el ecosistema de sabana, dos son las especies car- 
nivoras que lo realizan: el leopardo y la hiena. El leopardo que habita llanuras aluviales puede utilizar a veces en más de una ocasión un mismo árbol para guardar sus presas, cuando la llanura que ocupa está muy desprovista de este tipo de vegetación. Del mismo modo, cuando ocupa zonas amesetadas altas o áreas montanas y se instala en recintos cársticos, también sucle desplazar carcasas a semejantes refugios.

Por otro lado, la hiena realiza aportes de restos a las madrigueras. en determinadas épocas del año, tanto para alimentar a la progenie. como para aprovechar los individuos adultos el contenido cartilaginoso y medular de los huesos. La diferencia de la hiena con respecto al leopardo es que ésta desplaza restos y no carcasas, debido a que al ser gregaria, sólo puede hacerlo tras un consumo inicial de la presa y porque mediante una estrategia carroñera sólo suele conseguir restos.

Los factores que intervienen en esta conducta son de carácter biológico -capacidad de acceso y asimilación de ciertos alimentos (hienas) y nutrir a las crías- y ecológico -características del medio y presión trófica (leopardo)-.

Una vez comprendidas las tres estrategias, es necesario recapacitar sobre el efecto que éstas tienen en la acumulación postrera de restos óseos (Fig. 3) (Domínguez-Rodrigo, en prensa b). El consumo in situ de la presa no provoca mayor concentración de huesos que los pertenecientes a la carcasa en cuestión -siempre que no proceda a continuación un acto de carroñeo destructivo y/o dispersor de carácter intensivo-, por resultar raramente coincidentes dos episodios cinegéticos sobre un mismo punto. Del mismo modo, el desplazamiento periférico de las presas tampoco suele provocar la acumulación de restos que pertenezcan a más de un individuo, puesto que al ser un desplazamiento realizado próximo al lugar de obtención, éste dependerá siempre del sitio en que se consigue la presa. En tres años sucesivos de estudio de docenas de asociaciones de huesos debidas tanto a acciones predatorias observadas, como a eventos de deposición natural y actos cinegéticos pasados, sólo en un caso coincidieron asociados huesos de dos individuos distintos en un mismo entorno de unos $200 \mathrm{~m}^{2}$, sin ser una charca. Entre los especímenes pertenecientes a ambos existía una fuerte diferencia en el estado de alteración debida a la exposición subaérea, lo cual indicaba una separación temporal rele-

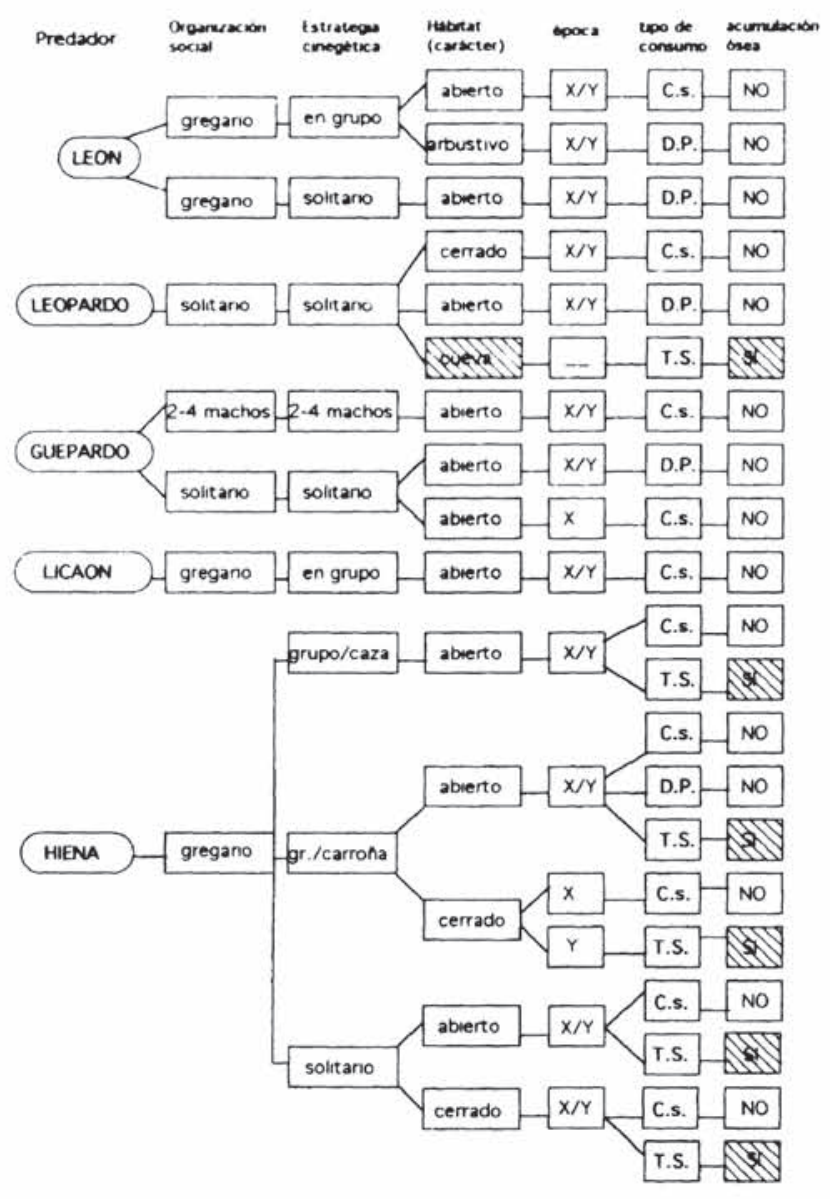

FIG. 3. Estrategias iniciales de consumo de los principales predadores y su relación con otras variables ecológicas. Clave: C.s. (Consumo in situ ), D.P. (Desplazamiento periférico), T.S. (Transporte sistemático), X (época de abundancia), Y (época de escasez).

vante entre las dos deposiciones. El raro amontonamiento óseo en los puntos de desplazamiento periférico se debe no sólo a su dependencia del lugar de obtención de la presa, sino a la presión trófica que lo propicia. He señalado anteriormente que dicho desplazamiento ocurre en contextos de presión trófica elevada -como son la zonas abiertas-, en los que el número y variedad de predadores es amplio. Este hecho es responsable también de que los animales carroñeros -cuya mayor actividad ocurre en este tipo de contexto ecológico- consuman y/o dispersen los restos abandonados tras la deposición generada después del desplazamiento inicial de la carcasa y su consumo. No hay que 
olvidar que los puntos periféricos a los que se desplazan las presas no son sino lugares de resguardo momentáneos, que no impiden el acceso a los restos por parte de otros carnívoros, sino que lo postponen lo suficiente para que un primer agente realice un consumo inicial.

Por estas mismas razones, el transporte reincidente que realiza el leopardo esporádicamente a un mismo árbol tampoco suele generar una acumulación ósea relevante. Esto se debe a que dicha reincidencia ocurre en contextos ecológicos abiertos en los que la presión trófica es alta, por lo que tras la caída de los huesos del árbol al suelo, las hienas acostumbran a desplazarlos del sitio y/o consumirlos. Sólo el transporte sistemático que realiza el leopardo a las cuevas y las acumulaciones que generan las hienas en sus madrigueras producen como resultado concentraciones importantes de huesos en porciones muy restringidas de terreno.

\section{ACUMULACIONES ÓSEAS PRODUCIDAS POR PROCESOS EN AUSENCIA DE TRANSPORTE}

El transporte sistemático de restos y carcasas que algunos carnívoros realizan no es la única forma natural de acumulación de huesos procedentes de varios individuos. Existen determinados enclaves que facilitan la deposición de diversas carcasas en áreas relativamente reducidas. Estos son los "lugares de predación en serie" y los "sitios de muerte en masa" (Haynes, 1988a, 1988b). Los lugares de predación en serie son puntos del paisaje en cuyo entorno inmediato tiene lugar una actividad cinegética intensa. Estos lugares coinciden -indistintamente del tipo de ecosistema- en hábitats abiertos -lugar en donde se concentra la biomasa herbívora y las especies carnívoras-, en puntos que favorecen la caza de animales -la mayor parte de las veces de manera estacional-, como son las charcas y las torrenteras de las llanuras aluviales. Esto se debe a que la necesidad de beber obliga a los animales, sobre todo en la época seca, a frecuentar las pocas charcas y otros lugares que mantienen agua, que son sitios que favorecen la presencia de carnívoros por la proximidad del agua y por la abundancia de animales que se concentra en su entorno. Estos lugares de predación intensa se caracterizan (Fig. 4) por una densidad de huesos mucho más reducida que las acumulaciones óseas generadas por un transporte sistemático. por una mayor abundancia de elementos axiales del esqueleto, por una subrepresentación de animales de menos de $150 \mathrm{~kg}$. de peso, por un número más reducido de individuos por área y por un patrón de dispersión y alteración de los huesos diferente (vease más adelante). En estos sitios resulta poco frecuente la superposición zonal en la acumulación de restos de individuos distintos.

Los lugares donde se generan acumulaciones debidas a un proceso de muerte en masa causadas por factores naturales, en los que la predación por parte de otros animales no interviene de manera relevante-, suelen ser enclaves cercanos a la sección proximal de llanuras aluviales, cauces hidraúlicos estacionales, y áreas empantanadas de humedad fluctuante. Menos comunes son otros sitios en los que se amontonan restos por efecto, por ejemplo, de la caída de parte de una manada de herbívoros por un acantilado, que dependerá de la ubicación de éste. Las razones de las muertes en masa en los lugares citados pueden ser varias; pero las más comunes son la situación ecológica en las épocas de sequía prolongada -estos sitios son los últimos reductos de agua (en su mayor parte sub-

\begin{tabular}{|c|c|c|c|c|}
\hline & nombre & Area & Densidad osea & Densidad MNI \\
\hline 1 & $\begin{array}{l}\text { charca de } \\
\text { los leones }\end{array}$ & $13.000 \mathrm{~m}^{2}$ & & $1 / 1083 \mathrm{~m}^{2}$ \\
\hline 2 & Ngamo* & $90.000 \mathrm{~m}^{2}$ & 1 hueso/ $125 \mathrm{~m}^{2}$ & $1 / 2571 \mathrm{~m}^{2}$ \\
\hline \multirow[t]{14}{*}{3} & Shabi Shabi * & $7500 \mathrm{~m}^{2}$ & 1 hueso/ $12 \mathrm{~m}^{2}$ & $1 / 214 \mathrm{~m}^{2}$ \\
\hline & HUESO & 1 & $2^{*}$ & $3^{*}$ \\
\hline & Cráneo & L50\% & $57 \%$ & \\
\hline & Mandibula & $50 \%$ & ar & 3694 \\
\hline & Vertehras & $18 \%$ & $23 \%$ & 1394 \\
\hline & Costillas & $1,5 \%$ & 69 & $15 \%$ \\
\hline & Escápula & $0 \%$ & $40 \%$ & 4126 \\
\hline & Huimero & $16 \%$ & 439 & 4494 \\
\hline & Badio & $16 \%$ & 3994 & 1394 \\
\hline & Cúbito & $12.5 \%$ & 319 & 3494 \\
\hline & Eémur & $38 \%$ & 439: & L619 \\
\hline & Tibia & $20 \%$ & $50 \%$ & $27 \%$ \\
\hline & Metápoda & $21 \%$ & $30 \%$ & 390 \\
\hline & Ealanoes & $0,9 \%$ & 398 & 198 \\
\hline
\end{tabular}

FIG. 4. Indices de densidad ósea y representación esquelética en dos lugares de predación en serie charca de los leones (Domínguez-Rodrigo, 1993) y *Ngamo (Haynes, 1988a)- y un lugar de muerte en masa -*Shabi Shabi (Haynes, 1988a)-. 
terranca) ! de plantas- o todo lo contrario. es decir, lat abundancia de agua. que puede provocar en los pantanos la muerte de animales que son incapaces de salir del barro y de los lodazales. y en los rios, determinadas conductas -como el paso del río Mara en el proceso migratorio de los herbivoros de las reservas del Serengeti (Tanzania) y Masai Mara (Kenia)- que provocan varias muertes coetáneas.

Fin los lugares en que ocurren estas muertes en masa suele existir una densidad de huesos por metro cuadrado mucho más reducidas que en las acumulaciones debidas at transportes sistemáticos de agentes biológicos. pero ligeramente mayor que en los lugares de predación en serie (Fig. 4). La representación esquelética es similar en las acumulaciones debidas a ambos tipos de procesos y depende de la intensidad de las acciones de carroñeo y exposición posteriores. La variedad taxonómica y de individuos de distintas dimensiones es parecida, existiendo del mismo modo escasos restos de carcasas de menos de $150 \mathrm{~kg}$. de peso. El número de individuos por área es mayor que en los lugares de predación en serie -con una media de uno cada ochenta metros cuadrados (Haynes, 1988a)-, pero aún así, bastante más reducido que en los amontonamientos de huesos producidos por transporte sistemático. Por esta razón, el solapamiento espacial en la dispersión de huesos de individuos distintos es poco frecuente y depende de los procesos de carroñeo posteriores.

\section{EL ESPECTRO CINEGÉTICO}

La mayor parte de los carnívoros suele tener acceso a una amplia diversidad de especies sobre las cuales pueden llegar a establecer preferencias. Este hecho se manifiesta con mayor claridad en los félidos, pues la tendencia general en el ámbito de los cánidos se inclina hacia un mayor eclecticismo. En el ecosistema de sabana disponemos de un claro ejemplo de aprovechamiento preferencial según las cualidades del predador. En el punto más elevado de predación se encuentra el león, cuyas presas pueden oscilar de 50 a $500 \mathrm{~kg}$. de peso. La variedad taxonómica sobre la que inciden es sumamente diversa; desde pequeñas gacelas hasta grandes búfalos. Sin embargo, en términos cualitativos la mayor parte de las capturas está constituida por presas de $250 \mathrm{~kg}$. en adelante, entre las cua- les el ñu y la cebra son los taxones más comunes. (on respecto al perfil de edades de las presas. los leones prefieren individuos adultos y sanos.

En el extremo opuesto se encuentra el guepardo. cuyo margen de predación queda establecido en torno a especies que pesan menos de 50 kg. . como la gacela. el impala o los ñus jóvenes. Sin embargo, es un cazador más especializado que el león. puesto que el $80 \%$ de sus presas son exclusivamente impalas o gacelas Thompson. La razón de esta diferencia entre ambos predadores $x$ debe por un lado a la incapacidad del guepardo en la caza de presas de gran tamaño y su mejor adecuación para la captura de presas más pequeñas y esquivas, $y$ a una menor necesidad de alimento ya que mientras que una carcasa pequeña resulta suficiente para abastecerle, sólo un animal grande suele ser suficiente para alimentar a una manada de leones no muy extensa.

Entre ambos términos podría situarse la actividad predadora del leopardo, cuya dieta incluye una auténtica variedad de presas, que van desde pequeños mamíferos hasta grandes bóvidos. No obstante, también en el leopardo se advierten preferencias que se deben a razones estratégicas. Dentro de la diversidad de especies a las que tiene acceso, este predador suele realizar hasta un $80 \%$ de su caza sobre ungulados de tamaño pequeño, inferiores a los $125 \mathrm{~kg}$. de peso (Kruuk \& Turner, 1967; Brain, 1981). La razón en este caso es doble. Por un lado el tamaño de la presa es más que suficiente para saciar sus necesidades y por otra parte, dado que el leopardo emplea una estrategia de desplazamiento periférico de las carcasas, si éstas pesan más de $125 \mathrm{~kg}$. le resultan muy difíciles de transportar. Por ello no es de extrañar que cuando cazan o carroñean una presa de mayor tamaño, lleven a cabo su consumo in situ y no trasladen, salvo excepciones, ninguna parte de la misma.

Con respecto a los cánidos, la estrategia de predación es distinta. Los cánidos grandes, como es el licaón en la sabana, cazan presas de todos los tamaños -con preferencia por las de tipo medio- y de cualquier especie accesible. Entre los cánidos menores, como el zorro y el chacal, la presa de mayor tamaño por ellos cazada no suele sobrepasar los $5 \mathrm{~kg}$. de peso. Sin embargo, bien es cierto que tienen acceso a especies mayores a través del carroñeo. Ocasionalmente el chacal puede capturar pequeñas gacelas Thompson (Haltenorth \& Diller, 1980). 
Fn el caso de los hiénidos la situación es ligeramente distinta. La hiena manchada interviene sobre una amplia diversidad de especies (ñu. gacela, cebra, antílope, facócero, etc...). No obstante, en claro contraste con el león. mantiene una preferencia por los individuos jóvenes y por los más viejos. En las acumulaciones de este tipo de hiénido existe una representación regular de animales de más de $125 \mathrm{~kg}$. Esto no sucede con la hiena parda, cuya representatividad de elementos óseos pertenecientes a una fauna de esas dimensiones es más bien reducida, predominando en cambio los ungulados de tamaño pequeño y existiendo un número relevante de restos de papión. Otro hecho sorprendente en los hábitos de esta hiena es el aporte a las madrigueras de pequeños carnívoros (chacal, zorro, lince...) que realiza sobre la carcasa entera y que suelen constituir del $40 \%$ al $50 \%$ de la acumulación ósea (Brain, 1981). Esta circunstancia explica que el índice de representación de elementos del esqueleto sea distinto del de la hiena manchada, y que predominen en las especies pequeñas los elementos axiales por ser los apendiculares mucho más aprovechables y más proclives a desaparecer. Igualmente en las especies de mayor tamaño, casi siempre por debajo de los $125 \mathrm{~kg}$. , los elementos axiales aparecen con cierta relevancia, pero la situación se invierte y los huesos de las extremidades son preponderantes, como ocurre con la hiena manchada.

Estos índices tan elevados de predación sobre carnívoros en el caso de la hiena parda no se dan en otros tipos de predadores, los cuales, no obstante, también interactúan cinegéticamente entre ellos mismos. El león, por ejemplo, incluye entre sus presas a leopardos, guepardos, chacales, hienas e incluso a otros leones. Algo similar ocurre con el resto de grandes carnívoros, quienes en su mayor parte cazan y son cazados por otros predadores.

En definitiva, las distintas especies de carnívoros establecen sus preferencias de caza en función de dos criterios: capacidad y necesidad. Cuanto mayor es el tamaño del carnívoro, mayor es su necesidad de ingesta cárnica diaria, con lo cual existe una convergencia entre dicha necesidad y la capacidad del carnívoro en cuestión en acceder a presas grandes, ya que su mayor dotación biológica así se lo permite. Sin embargo, si esta aseveración es válida para los carnívoros hegemónicos, como es en la actuali- dad el leon. debe ser levemente matizada para los carnivoros medianos puesto yue en éstos el criterio de capacidad se establece en torno a dos factores: la posibilidad de captura en sí y la capacidad de poder trasladar la presa obtenida. Por consiguiente. en los carnivoros intermedios e incluso en los menores. lo que cuenta es una necesidad de abastecimiento más reducida y una capacidad de aceeder a presas yue sean transportables. De ahi que el espectro taxonómico general del leopardo y del guepardo se encuentre en especies cuyo peso está por debajo de $125 \mathrm{~kg}$. De este modo las presas del leopardo son de mayor tamaño que las del guepardo. porque su capacidad física de traslado y su necesidad también son algo mayores (Frame, 1981).

Esta afirmación, en principio dirigida a los félidos resulta también aplicable -aunque con las debidas correcciones- a los cánidos y hiénidos. En este caso el tamaño corporal no determina el acceso a las presas grandes, como ocurre entre las hienas manchadas y los licaones, sino el tamaño del grupo, que es el que posibilita. en una cooperación gregaria, la obtención de una víctima grande (criterio de capacidad) y que la justifica no por la facilidad o no de traslado -ya que éste, en el caso de los hiénidos, opera sobre partes del esqueleto y no sobre toda la carcasa- sino por el menester de abastecer a los varios miembros que conforman el grupo (criterio de necesidad). De este modo, hienas manchadas y licaones, al ser los más gregarios y numerosos entre los cánidos y hiénidos de la sabana y estepa africanas, son los más capacitados para -y necesitados de- la captura de presas grandes. Esto justifica la selección de presas de menores dimensiones por parte de animales como la hiena parda, bastante más pequeña y mucho menos gregaria, siendo poco común su aparición en grupo.

\section{PATRONES DE ALTERACIÓN ÓSEA}

El modo en que un predador consume su presa condiciona la gama de elementos que sobreviven a dicho proceso y su estado de alteración. En términos generales, tres son las áreas de estudio en las que puede centrarse este tipo de investigación: el análisis porcentual de la representación ósea, el estado de cada hueso y la presencia y tipo de marcas de dientes. 
A continuación expondré los principales patrones de alteración ósea realizados a lo largo del consumo de las carcasas por parte de los grandes carnivoros africanos. Este tipo de estudio lo he realizado principalmente en la reserva natural de Masai Mara (Kenia) y en el parque natural del Serengeti (Tanzania), sujetos a una variación cíclica de los recursos faunísticos, cuya regulación orográfica depende de procesos migratorios, por lo que el periodo de abundancia se sitúa a grandes rasgos en la época seca larga (Junio-Octubre) y el periodo de escasez. en la época húmeda (Marzo-Mayo). dependiendo de la zona elegida en cualquiera de los sitios citados.

LEÓN (Fig. 5)- En lo que concierne al porcentaje de representación esquelética, éste suele ser muy elevado en cada elemento óseo, ya que el león sólo consume la carne y las vísceras y no altera los huesos hasta el extremo de hacerlos desaparecer o no identificables. La excepción radica en el consumo de individuos juveniles o infantiles, en los que el índice de elementos axiales -vértebras, costillas y pelvis-, al igual que el de los huesos superiores de las extremidades, puede sufrir una ligera disminución, al experimentar un proceso de mayor deterioro.

El modo en que este félido altera los huesos de sus presas depende de factores ecológicotemporales. Con respecto a éstos, en la época en la que los recursos abundan, los leones pueden dejar intactos los huesos de una carcasa, ya

\begin{tabular}{|c|c|c|c|c|c|c|c|}
\hline \multirow[b]{3}{*}{ HUES } & \multicolumn{3}{|c|}{ LEON } & LEOPARDO & GUEPARDO & \multicolumn{2}{|c|}{ HIENA } \\
\hline & \multicolumn{2}{|c|}{ M.A. } & M.D. & \multirow{2}{*}{$\begin{array}{l}\text { M.A. M.D } \\
\text { Todo el ano }\end{array}$} & \multirow{2}{*}{\begin{tabular}{|l|} 
M.A. M.D \\
Todo el ano
\end{tabular}} & \multicolumn{2}{|c|}{ M.A. M.D. M.A. M.D } \\
\hline & & $\mathbf{Y}$ & $X Y$ & & & cartoroada & madnguera \\
\hline $\begin{array}{l}\text { Cráneo } \\
\text { Mandíbula } \\
\text { Vertebras } \\
\text { Costillas } \\
\text { Escápula } \\
\text { Húmero } \\
\text { Radio } \\
\text { Cúbito } \\
\text { Fèmur } \\
\text { Tibia } \\
\text { Metápodo } \\
\text { Falanges } \\
\text { Pelvis }\end{array}$ & 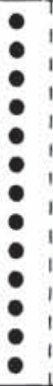 & 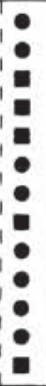 & $\begin{array}{l:l}\text { P } & P D \\
S & S D \\
E & E \\
& D S \\
& E \\
D & D M S \\
D & D \\
E & E \\
D & D M S \\
& D \\
& \\
& \\
& P S D\end{array}$ & 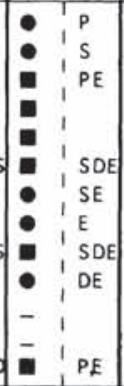 & 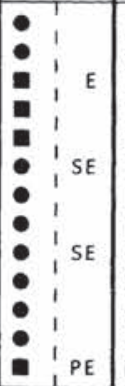 & 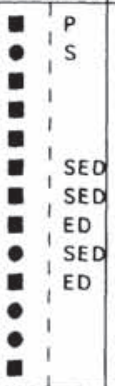 & 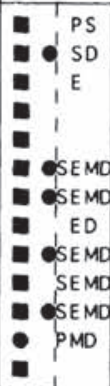 \\
\hline & & & $\begin{array}{l}X-\text { epoc } \\
\text { Y- ероc }\end{array}$ & $\begin{array}{l}\text { ca de abundar } \\
\text { ca de escasez }\end{array}$ & cia & $\begin{array}{l}\text { alterac } \\
\text { alterac }\end{array}$ & $\begin{array}{l}\text { fuerte } \\
\text { menor }\end{array}$ \\
\hline D. depres & & $M-m$ & rdisqueo & S- surco & - perforación & $\begin{array}{r}\text { E-Extracci } \\
\text { del te }\end{array}$ & $\begin{array}{l}\text { ejón } \\
\text { ejido oseo }\end{array}$ \\
\hline
\end{tabular}

Fig. 5. Patrones de alteración ósea según el tipo de predador y el contexto temporal y deposicional (hiena). que tras eventrarla suelen consumir la carne de la sección abdominal y lumbar y la de los cuartos traseros, dejando el resto de la pieza entera a disposición de los buitres. En esta circunstancia no queda ningún indicio. por el estado de los huesos, que demuestre dicha acción cinegética. En casos normales, la destrucción ósea que llevan a cabo consiste en la apertura de la caja torácica en el acto de eventración, lo que conlleva la fragmentación de los extremos distales de las costillas en mayor o menor grado. Del mismo modo, las apófisis superiores de las vértebras dorsales y las apófisis laterales de las vértebras lumbares suelen fragmentarse a distinta altura. Uno de los patrones más curiosos que he podido documentar ha sido la aparente relación que existe entre los modos de alteración de los huesos axiales, dependiendo de la intensidad del proceso destructivo. En las épocas de abundancia, los leones apenas alteran las carcasas -como acabo de mencionar-o, en caso positivo, lo hacen fracturando el tercio distal de las costillas y dejando intactas las apófisis vertebrales o quedando afectada tan sólo una porción reducida de sus extremos -proceso de alteración menor (AM)-. En épocas de carestía o en circunstancias de intervención de manadas extensas de leones -a lo largo de todo el año-, el proceso de alteración es más fuerte (AF). Las costillas pueden quedar reducidas hasta dos tercios de su longitud -permaneciendo la sección proximal-y las apófisis de las vértebras dorsales y lumbares experimentan idéntico efecto, quedando tan sólo la base que las une al cuerpo vertebral. En este caso, hasta las vértebras cervicales resultan afectadas.

Cuando opera este proceso de alteración ósea fuerte $(\mathrm{AF})$, las extremidades, que normalmente permanecen intactas, pueden aparecer con ligeras modificaciones: ausencia de la epífisis proximal del húmero $\mathrm{y}$, en caso de que la presa sea menor de $150 \mathrm{~kg}$. de peso, fracturación de los estilopodios. Por lo restante, los huesos apendiculares conservan su integridad.

Sin embargo, estos modos de alteración se pueden observar en huesos pertenecientes a presas de tamaño medio -superior a los 250 kg.-, pero no en aquellas pequeñas, menores de 100 $\mathrm{kg}$. En este caso, el proceso de destrucción es mayor, pudiendo desaparecer la mayor parte del esqueleto axial -vértebras, costillas y pelvis-, aparecer el cráneo alterado -sobre todo en su parte frontal- o destrozar la escápula, que en los 
individuos de especies mayores se conserva. fracturar húmeros y fémures y. más raramente. alterar la tibia.

Con respecto a las marcas de dientes (1) que pueden aparecer en los distintos huesos, éstas son como detallo a continuación:

Perforaciones. - Suelen ser raras y aparecen en el cráneo -tanto en su sección superior, como en lateral- y en el ilión de la pelvis. Excepcionalmente pueden observarse en las costillas.

Surcos. - Sumamente raros en los procesos de alteración menor $(\mathrm{AM})$, pueden aparecer, en época de escasez de recursos -en la que las carcasas se procesan con más intensidad-, en húmeros y fémures (incluso en las trócleas), sobre todo de individuos de tamaño pequeño. Menos frecuentes -pero desligados del criterio temporal- pueden observarse también en la pelvis.

Mordisqueo. - Raro. Aparece, condicionado por las estrategias adoptadas frente a la disponibilidad de recursos, en húmeros y fémures, asociado a los surcos. Suele ser más común la aparición de depresiones aisladas en estos huesos y a veces en las vértebras y en la sección superior de las tibias.

Extracción de tejido óseo. - Ocurre en los procesos de alteración ósea fuerte $(\mathrm{AF})$ en las apófisis vértebrales, en las epífisis de los estilopodios -muy raro que aparezca en las epífisis de la tibia y, en menor grado, en la del radio-cúbito, a no ser que se trate de especies o individuos menores de $150 \mathrm{~kg}$. de peso-, y en el ilión e isquión de la pelvis.

LEOPARDO (Fig. 5)- El índice de representación esquelética en los lugares donde genera acumulaciones por efecto de transporte sistemático muestra un porcentaje elevado de elementos óseos apendiculares -con respecto a la presencia original- y más reducido, en proporción, de huesos axiales -aunque similar a veces en el conjunto global-, en el que destacan vértebras y, sobre todo, costillas. Los metápodos, radio-cúbitos y tibias -estos dos últimos a

(1) He optado por traducir los términos icnológicos anglosajones tal y como expongo a continuación: perforación (puncture), depresión (pit), mordisqueo (pitting), surco (score) y extracción de tejido óseo (furrowing). Esta última definición tal vez no es muy acertada, pero la considero más apropiada que "roído", más atribuíble a la acción de los roedores. veces en sus mitades distales, según el proceso destructor- suelen estar bien representados, y los huesos superiores de las extremidades son más escasos. encontrándose muchas veces ausentes o bien muy alterados -con presencia de epífisis distal- A este respecto, existe un sesgo a favor de la conservación en mejor estado del fémur con respecto al húmero. Pelvis y escápulas suelen estar poco representadas, siendo poco frecuente su aparición. Cráneos y mandíbulas son, en cambio. los elementos más abundantes (Brain, 1981).

El patrón de alteración exhibido por este félido en los puntos a los que desplaza a sus presas, al igual que sucede con el guepardo, es más regular que el creado por el león. En lo que concierne a los bóvidos, que comprenden la mayor parte de su alimentación, suele dejar intacta la sección inferior de las extremidades (metápodos, falanges...) y el cráneo y la mandíbula. La sección intermedia de las extremidades (tibia y radio-cúbito) puede resultar escasamente afectada o, en caso contrario, quedar fracturada por el tramo proximal de la diáfisis, desapareciendo las epífisis proximales. Con respecto a los huesos axiales -pelvis, costillas y vértebras-, éstos pueden desaparecer casi por completo. Lo único que queda menos alterado es la cabeza y, en menor grado, algunas vértebras cervicales. Sin embargo, este tipo de alteración extrema no es la norma habitual.

Si se detalla este proceso de alteración, con respecto a la conducta del leopardo he observado dos grandes patrones de modificación ósea que no he podido relacionar con factores ecológicos de abundancia o escasez de recursos. $\mathrm{El}$ proceso de alteración fuerte $(\mathrm{AF})$ provoca una relación curiosa en la forma en que se modifican los huesos axiales y apendiculares. Cuando ocurre, es frecuente que no existan apenas vértebras y costillas, la pelvis y la escápula desaparecen y las extremidades se alteran del modo señalado anteriormente: los estilopodios desaparecen y los zigopodios pueden mostrar una ligera modificación o ausencia de epífisis y metadiáfisis proximal. En este caso el cráneo puede aparecer intacto o fragmentado.

En el extremo opuesto, el proceso de alteración menor (AM) favorece la conservación de restos axiales -las vértebras y, en menor medida, las costillas aparecen en proporciones significativas- aunque la pelvis suele fracturarse a menudo y desaparecer, y los huesos apendiculares 
sucken encontrarse intactos o en tode caso con alteraciones menores en las epifisis. Las apófisis vertebrales pueden aparecer intactas -sobre todo las pertenecientes a las vértebras dorsaleso fragmentadas. Fl cráneo y la mandíbula pueden mantenerse inalterados o ser fragmentados. Este tipo de proceso modificador se da con mayor frecuencia en las especies mayores del espectro cinegético del leopardo: es decir. aquéIlas situadas entre los $7(0-150 \mathrm{~kg}$. de peso. El proceso de alteración fuerte. en cambio, suele darse en carcasas más pequeñas.

Con respecto a las improntas generadas en la superficie ósea por todo el proceso de alteración y consumo de la carcasa (marcas de dientes), éstas suelen ser escasas. Tanto en las acumulaciones generadas por transporte sistemático, como por desplazamiento periférico sobre especímenes individuales, no sobrepasa normalmente el $25 \%$ de todo el conjunto (Brain. 1981: Domínguez-Rodrigo, en prensa b). A nivel más específico, las marcas se ubican, según el tipo. como detallo a continuación:

Perforaciones.- Suelen aparecer en el cráneo, indistintamente del proceso de alteración que opera sobre el resto de la carcasa. También pueden observarse de manera esporádica en el ilión de la pelvis, cuando ésta no sufre un proceso destructor absoluto. En el proceso AM pueden aparecer en la base de las apófisis de las vértebras dorsales: aún cuando esto no sea muy frecuente.

Surcos.- De distribución más amplia, los surcos pueden observarse en la mandíbula, en el ilión e isquión de la pelvis y, de manera aislada y ocasional, en la diáfisis de los estilopodios. No es frecuente que la tibia muestre alguno, aunque sí el radio. Cuando aparecen en estos huesos, suele ser en forma de escasas señales, próximas a las epífisis. En un proceso AF sí pueden aparecer en mayores cantidades y a lo largo de la diáfisis.

Mordisqueo.- Muy raro. En un proceso AF a veces se observan depresiones en las diáfisis de las tibias.

Extracción de tejido óseo.- Es la impronta más frecuente que realiza este tipo de predador. Suele observarse mejor en procesos AM. Aparece en las apófisis vertebrales, en el ilión e isquión de la pelvis y en las epífisis proximales de estilopodios y zigopodios.
GUEPARIOO(Fig. 5)- Este animal suele ser tan regular como el leopardo en los tipos de alteración ósea que imprime a sus presas. Comprendidas éstas dentro de la gama de bóvidos pequeños, el guepardo las modifica siguiendo un doble patrón. mostrado a través de bóvidos más pequeños (gacelas Thompson) y bóvidos algo mayores (Impala). El primero consiste en la destrucción del esqueleto axial, desapareciendo la práctica totalidad de vértebras y costillas. junto con la pelvis y escápula y quedando tan sólo la cabeza -a veces fragmentada- y las extremidades, por lo general intactas o en las que el húmero también ha desaparecido. El otro modo de alteración, también exhibido con algunas gacelas pero mejor ilustrado con el procesamiento de los impalas y otros bóvidos similares, consiste en la pervivencia de los huesos axiales, pero en estado de gran modificación. Las costillas pueden quedar reducidas a más de la mitad de su longitud y las apófisis de las vértebras -sobre todo las lumbares- resultan fracturadas. Pelvis y escápulas también sobreviven al consumo y tanto los huesos del cráneo, como los de las extremidades quedan casi intactos.

En lo que concierne a las marcas de dientes, éstas aparecen aún con menor frecuencia que en el caso del leopardo:

Perforaciones.- Son muy raras. En mi estudio sólo he podido detectarlas y de manera excepcional en el ilión de la pelvis.

Surcos.- Igualmente poco frecuentes, pueden aparecer en los estilopodios.

Mordisqueo.- No observado. Alguna depresión aislada.

Extracción de tejido óseo.- Al igual que en el caso del leopardo, es el tipo de impronta más frecuente. Aparece en las apófisis vertebrales, en el ilión e isquión de la pelvis y, con menor frecuencia, en las epífisis proximales del fémur y húmero -sobre todo en este último-.

HIENAS (Fig. 5)- La representación esquelética presente en las acumulaciones óseas que las hienas manchadas generan en sus madrigueras, mediante el transporte sistemático de restos, se caracteriza por la abundancia de huesos pertenecientes a las extremidades y cabeza y la ausencia de elementos axiales. Abundan fémures y radios -con sesgo representativo de la epífisis distal-, húmeros y tibias -con sesgo representativo de la epífisis proximal-, metápodos y 
falanges. Mandíbulas y. en menor medidat fragmentos de cráneo y cuernos son tambićn abundantes (Domínguez-Rodrigo, en prensa b).

En lo que respecta a los patrones de alteración ósea. la captura de una presa por parte de una manada de hienas manchadas, sin tener en cuenta su tamaño, resulta -si la manada la componen más de media docena de individuos- en la práctica desaparición y dispersión de los huesos de la misma. Paralelamente al proceso de eventración, las hienas consumen y fracturan costillas y vértebras y acto seguido hacen lo mismo con la pelvis y escápulas. Tras este acto inicial, la competencia de los miembros del grupo resulta en la desarticulación de la carcasa y la separación de las extremidades y de la cabeza -generalmente con algunas vértebras cervicales- del resto del esqueleto. A continuación tiene lugar un acto de consumo secundario, en el que se aprovechan las epífisis de la mayor parte de los huesos apendiculares de la sección superior e intermedia de las extremidades y se fracturan algunas diáfisis o fragmentos largos de las mismas. Por lo general, los metápodos permanecen intactos en esta fase y pueden ser desplazados posteriormente. La cabeza también se fractura, para ganar acceso al contenido interno. Tras un proceso de estas características, la mayor parte de la carcasa desaparece. Sin embargo, este tipo de proceso resulta más observable en épocas de escasez de recursos o épocas intermedias, en las que las hienas deambulan en números importantes y realizan actos cinegéticos. En épocas de abundancia, las hienas experimentan en algunas zonas un curioso fenómeno: se escinden con mayor frecuencia y establecen grupos familiares reducidos. En este momento -en el que no realizan aportes a las madrigueras-, en determinadas áreas la disposición de carroña les permite incluso hasta ser selectivas en el alimento obtenido mediante esta estrategia. Al ser menos en número(frecuentemente una o dos), no causan el mismo efecto en las carcasas, y cuando acceden a una, si han podido carroñear suficiente en otro lugar, ni siquiera la tocan o aprovechan los restos escasos de carne que puedan quedar. El tuétano óseo resulta, pues, de interés secundario. Incluso puede verse, a pesar de su evidente predilección por los huesos axiales (Marean et alii, 1992), que el comportamiento subsistencial de estos hiénidos se vuelve en esta época más aleatorio, consumiendo el cartílago de algunas epífisis de los huesos apendiculares y no alterando apenas los restos axiales o crancales.

In lo que concierne a las marcas de dientes. en un proceso de alteración fuerte como el descrito no quedan marcas porque casi no quedan huesos. No obstante. en las intervenciones sobre carcasas mediante actos de carroñeo, éstas si pueden observarse en frecuencias por lo general menores del $20 \%$ del conjunto (Blumenschine. 1988). En su mayor parte aparecen en las secciones finales de las diafisis, generadas por el consumo de las epifisis (Blumenschine, 1988: Blumenchine \& Marean, 1993). En este tipo de contexto las marcas que aparecen son:

Perforaciones.- Nulas. Pueden aparecer en el cráneo.

Surcos.- En las secciones finales de las diáfisis.

Mordisqueo.- Raro. Suelen aparecer depresiones aisladas asociadas a los surcos.

Extracción de tejido óseo.- Relativamente frecuente; sobre todo en los huesos apendiculares cuyas epífisis no han sido consumidas por completo.

El panorama de representación de marcas de dientes cambia de los lugares de predación o carroñeo a las acumulaciones creadas en las madrigueras. En principio, el índice de representación es mucho más elevado, situandose entre un $60 \%-100 \%$, con una media superior al $80 \%$ (Blumenschine, 1988; Blumenschine \& Marean, 1993). Los tipos de marcas están mejor representados:

\section{Perforaciones.- Muy raras.}

Surcos.- Aparecen en la mayor parte de los huesos, sobre todo a lo largo de la diáfisis de los huesos apendiculares. Suelen mostrarse en gran número en porciones reducidas de hueso.

Mordisqueo.- Muy frecuente. Aparece relacionado con los surcos. A veces existen depresiones aisladas.

Extracción de tejido óseo.- Observable, al igual que en los lugares de carroñeo, en las epífisis que no se han consumido por completo.

CHACAL- No suele cazar -con excepción de individuos de gacelas Thompson juveniles e infantiles-y los huesos que altera proceden de carcasas abandonadas por otros carnívoros. El proceso de alteración que efectúa en éstos suele ser leve. Tiene predilección por los huesos 
apendiculares por ser más fáciles de desplazar, al no estar articulados como los restos axiales, y su forma de modificarlos es mordiendo el cartílago epifisario de huesos intactos y/o la diáfisis en los huesos en los que las epífisis ya han sido alteradas. Las marcas de dientes que deja, por consiguiente, en la superficie de estos huesos se distinguen de las de otros agentes por aparecer con más frecuencia en las secciones centrales de las diáfisis.

\section{PROCESOS DE DISPERSIÓN DE HUESOS Y SU ANÁLISIS ESPACIAL}

Los agentes biológicos pueden modificar un conjunto óseo de dos maneras: alterando los huesos físicamente y dispersándolos. La Tafonomía se ha centrado más en las distintas categorías analíticas del primero que del segundo aspecto, por disponer de un marco referencial que en el caso de los modelos de dispersión no existía hasta ahora. Sin embargo, es posible establecer diagnosis válidas de discriminación de agentes a partir del análisis espacial de los restos de las carcasas. A grandes rasgos, pueden diferenciarse dos niveles de análisis en este tipo de investigación. El primero está dirigido al discernimiento de núcleos de densidad general -el objeto es descubrir los puntos de mayor incidencia en la utilización del espacio- y el segundo trata los cúmulos de densidad de atributos concretos -pretendiendo hacer inteligibles actividades y agentes determinados-. Para uno y otro tipo de análisis se carece en la actualidad de un marco conceptual que no sea estadístico y que se ocupe por lo tanto de no primar consideraciones cuantitativas sobre aproximaciones cualitativas al registro material. El que aquí propongo brevemente -y que se amolda a semejante propósito- engloba a un conjunto somero, compuesto por las siguientes definiciones, que ya formulé en otro trabajo (Domínguez-Rodrigo, 1993):

ASOCIACIÓN SIGNIFICATIVA.- Concentración de objetos del mismo o distinto material, que se encuentran dispersos en un área tan delimitada que forman un amontonamiento singular, separado de los restantes por una o varias zonas de interconexión.

ÁREA SIGNIFICATIVA.- Recibe esta denominación una sección espacial dentro de un yacimiento, en la que confluyen o existen varias asociaciones significativas o diversos conjuntos de relación.

CONJUNTO DE RELACIÓN.- Comprende el global de elementos pertenecientes a la misma o a distintas asociaciones significativas que se encuentran interrelacionados por compartir un mismo carácter. Si el conjunto de relación se encuentra dentro de los márgenes de una asociación recibe el calificativo de "endógeno', y si lo hace fuera de ella -con una zona de interconexión o con otras asociaciones significativas-, se denomina "exógeno".

ZONA DE INTERCONEXIÓN.- (Zona intermedia). Extensión irregular y variable que separa una asociación significativa de otra. Se caracteriza por estar constituída por una ausencia de objetos o por una dispersión amplia de materiales, que implica una densidad de los mismos por unidad territorial sumamente baja, en comparación con las asociaciones significativas.

INTERSECCIÓN.- Solapamiento entre materiales de asociaciones próximas o entre conjuntos de relación cercanos.

La forma en que cada carnívoro dispersa los restos en un plano espacial depende básicamente del carácter de su organización social, del tipo de hábitat y del momento de acceso a los mismos (primario/secundario). La dispersión diferencial de elementos óseos tiene lugar siguiendo el criterio de pérdida de densidad según se aleja uno del área focal de acumulación de huesos. Siguiendo dicho criterio, y basándose en la observación de los procesos de desarticulación que operan en las carcasas durante y tras los actos cinegéticos, cabe diferenciar tres zonas de acumulación (Fig. 6a), tomando como referencia el lugar de deposición original de la carcasa -debida a la caza de un predador o a su muerte natural- o su punto de desplazamiento periférico:

Área A.- Abarca un radio aproximado de 2 m. y suele ser la zona con mayor concentración de huesos. Estos pueden comprender una carcasa completa o parcial. En este último caso, los huesos acumulados son en su mayor parte axiales y cráneo-mandibulares.

Área B.- Posee un radio de $6 \mathrm{~m}$., tomando como eje el punto central del área $\mathrm{A}$. Al situarse en torno a la misma, posee una concentración de restos menor y éstos suelen ser de tipo apendicular, aunque en ocasiones algunos pueden ser de tipo axial y craneal. 
Área C.- Se sitúa en torno al área B y abarca un radio aproximado de $12 \mathrm{~m}$. tomando como eje el punto central del área A. En este área los huesos que aparecen -de manera dispersa- son de tipo apendicular, siendo menos frecuente que aparezca algún hueso axial o cráneo-mandibular.

Fuera de este área es posible la dispersión de huesos en una amplia zona periférica, que puede abarcar varias decenas de metros y que se denomina "zona de dispersión externa". Desde una consideración de acceso primario a la presa, existen los siguientes modos de distribución ósea (Fig. 6c):

Modalidad 1: todos los restos se concentran en el área A.- Puede ser el resultado de la muerte natural del animal o de su captura por un félido. Ocurre en el caso en que el leopardo no traslada su presa, y en los guepardos solitarios y es una de las formas de aprovechamiento utilizada por los leones en cualquier tipo de hábitat, preferentemente los que ocupan las llanuras de gramíneas.

Modalidad 2: los restos se distribuyen en las áreas A y B.- En este caso, mientras los huesos axiales y craneales -junto con la mandíbulapermanecen en el área $\mathrm{A}$, los apendiculares -y a veces también los cráneo-mandibulares, junto con algunas vértebras- pueden aparecer en el área $\mathrm{B}$ por efecto de la desarticulación de la carcasa. Esto tiene lugar en cazadores gregarios y por ello es lo que ocurre en el caso de manadas de leones, de la intervención de tres o cuatro guepardos machos y, probablemente, de la acción de licaones, tal y como puede observarse en otros cánidos gregarios.

Modalidad 3: los restos se dispersan en las áreas A, B y C.- En este caso, lo mismo que en el anterior, los huesos axiales suelen permanecer en el área A, mientras que el cráneo, mandíbula y extremidades pueden aparecer distribuídos en las áreas $\mathrm{B}$ y $\mathrm{C}$. También resulta frecuente que los huesos axiales se desplacen del área A a cualquiera de las otras dos, dejando dicha zona un tanto vacía. Normalmente los restos que aparecen en las áreas B y C suelen distribuirse de manera radial, puesto que es el resultado de la acción de desarticulación debida a la competencia de los miembros del mismo grupo y lo que se intenta es desgajar una porción y desplazarla ligeramente del foco central para consumirla sin ser molestado. Es el re- sultado de la intervención de predadores gregarios, como los leones, entre los félidos- esta modalidad no la he observado nunca en guepardos pseudo-gregarios-, los licaones, entre los cánidos, y las hienas manchadas, entre los hiénidos.

Sin embargo, la configuración espacial de unos restos debida a una acción de intervención primaria sobre una carcasa puede resultar ulteriormente modificada por una acción de inter-

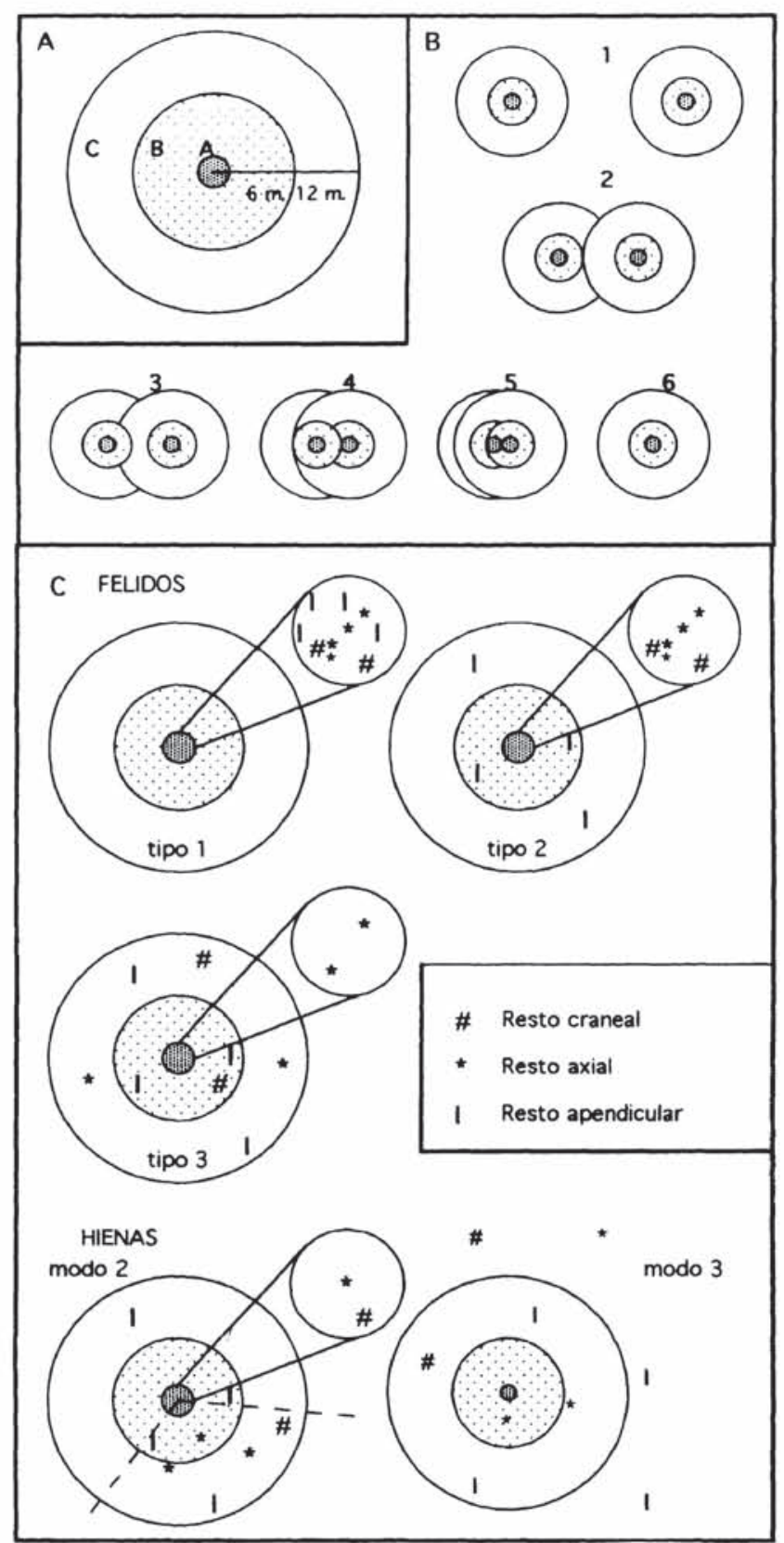

FIG. 6. (A) Configuración de la unidad básica de distribución inicial de huesos de un individuo. (B) Distintas configuraciones entre dos asociaciones significativas. (C) Patrones de dispersión ósea según el tipo de predador (félido-hiénido). 
vención secundaria. La mayor parte de este tipo de intervenciones oportunistas la llevan a cabo, por este orden, hienas y chacales. A lo largo de mis observaciones de campo he podido constatar que, al igual que los félidos, las hienas muestran tres modalidades de dispersión de restos, que pueden aplicarse tanto en el consumo de sus presas -aunque raramente-, como en el aprovechamiento terminal de los restos dejados por otros predadores (Fig. 6c). Estas son las siguientes:

$1^{\circ}$ Alteración y consumo de restos en el lugar en el que los encuentran.

$2^{\circ}$ Movilización dentro de las áreas A, B y $\mathrm{C}$, generando sectores de acumulación de cierta densidad.

$3^{\circ}$ Movilización de restos fuera del área $\mathrm{C}$, provocando su dispersión aislada.

En el primer caso, las hienas no alteran la modalidad de dispersión de una asociación significativa generada por otro agente, pero sí provocan la aparición de conjuntos de relación distintos, ateniendose a atributos complementarios como son los índices de representación de elementos del esqueleto y las marcas de dientes. La tendencia a consumir vértebras y pelvis y los segmentos epifisarios de los huesos apendiculares puede hacer que el número de restos craneales y axiales sea bajo y que exista un sesgo en la representación de los elementos óseos de las extremidades a favor de las secciones inferiores. Del mismo modo, los conjuntos de relación de marcas de dientes son determinantes no tanto por los índices de representación, que en estos casos oscilan sobre un espectro similar, sino por la abundancia relativa según el tipo de huesos. En las intervenciones de hiénidos en acumulaciones ajenas, el número de marcas de dientes presentes en metápodos y zigopodios es más amplio que en las acumulaciones exclusivas de félidos. Este tipo de comportamiento se manifiesta cuando interviene una sola hiena, ya que sin la presión ejercida por la competencia de otros compañeros y por los criterios jerárquicos de su modo de interacción social, puede procesar los huesos en el punto donde los encuentra.

En el segundo caso, las hienas provocan cierta alteración de los huesos, desplazando generalmente los restos del área $\mathrm{A}$ a las áreas $\mathrm{B}$ y $C$, pero de manera opuesta a como lo hacen otros carnívoros. Mientras que éstos lo hacen de un modo radial, en el que la dispersión significa disgregación, las hienas pueden desplazar los restos generando una concentración sectorial en estas zonas periféricas (Fig. 6c). Por supuesto que estas asociaciones significativas poseen conjuntos de relación en los que los elementos esqueléticos aparecen sesgados, del mismo modo que en la primera modalidad. Sin embargo, una de las características de esta modalidad es que rompe la disposición de contrarios, típica de félidos, en la que mientras que el área $\mathrm{A}$ alberga restos craneales y axiales, las áreas periféricas sólo contienen huesos de las extremidades o cuando aparecen restos axiales, lo hacen en un patrón de dispersión abierta, en el que no suelen mezclarse elementos opuestos. En esta segunda modalidad, las hienas también desplazan huesos craneales y axiales a las áreas B y C, pero lo hacen mezclándolos con los huesos apendiculares, generando conjuntos de densidad variable. He observado que este comportamiento se manifiesta cuando intervienen dos o tres hienas en un conjunto óseo. Esto puede deberse a que si bien la competencia es relajada, interponen no obstante un espacio pequeño entre ellas.

En última instancia, las hienas son los únicos carnívoros de sabana que desplazan restos con regularidad fuera del área $\mathrm{C}$, lejos del lugar de deposición original de la carcasa (Fig. 6c), formando -al contrario del caso precedente- una dispersión que no produce un solapamiento de restos de ningún tipo. Estos pueden aparecer en estado semi-intacto o procesados, con lo cual el número de fragmentos puede llegar a ser abundante. Las distancias a que pueden deplazarse estos restos son variables y se extienden desde una veintena de metros del límite externo del área $\mathrm{C}$ hasta más de dos kilómetros.

Pero las hienas no son los únicos animales que desplazan huesos a las "zonas de dispersión externa". Los chacales acostumbran hacerlo con asiduidad, en especial sobre huesos pertenecientes a las extremidades. Del mismo modo, los leones que habitan las llanuras abiertas de sabanas y estepas arbustivas suelen recurrir a la estrategia de desplazar restos -generalmente apendiculares y, en menor grado, cranealesfuera del área C y a gran distancia (200-300 m.) del punto de deposición original, buscando la sombra de los arbustos.

Sin embargo, hasta aquí he expuesto sucintamente las formas de dispersión de restos pertenecientes a un sólo individuo. Aunque en todo tipo de contextos ecológicos, las distintas 
variantes de la dinámica trófica no propician regularmente la conjunción en una misma cona reducida de elementos óseos pertenecientes a individuos distintos, puede darse el caso de que esto ocurra, sobre todo en puntos de transporte sistemático, lugares de predación en serie (Domínguez-Rodrigo, 1993) o enclaves de muerte en masa.

Desde un plano teórico existen cinco modos de contacto entre asociaciones significativas (2) distintas (Fig. 6b). La primera de ellas implica la existencia de una zona intermedia o de interrelación, de dimensiones variables, que mantiene las asociaciones separadas (Configuración 1). La segunda forma se establece a partir de la ausencia de zona de interrelación entre al menos dos asociaciones, entrando el área $\mathrm{C}$ de cada una en contacto (Configuración 2). Dentro de este tipo de configuración, al igual que en las siguientes, existen diversas modalidades -A, B, C, etc...-, según el número de asociaciones intercomunicadas $-2,3,4$, etc..., respectivamente-. La tercera forma de conexión es que el área $\mathrm{C}$ de una asociación englobe al área B y C de la asociación opuesta (Configuración 3). Una cuarta forma la constituye la unión de las áreas B de al menos dos asociaciones significativas diferentes, entrando el área $\mathrm{C}$ de cada una en conexión con todas las áreas de la asociación opuesta (Configuración 4). La cuarta modalidad la forma la intromisión de las áreas $\mathrm{A}$ de asociaciones diferentes en las áreas B de cada una de ellas (Configuración 5). La última forma la constituye, finalmente, la interconexión espacial de las áreas A de cada una de las asociaciones que intervienen (Configuración 6).

$\mathrm{Si}$ se combinan estas cinco configuraciones con cada una de las tres modalidades de dispersión que hemos visto en la sección anterior, existen, teóricamente, hasta treinta resultados distintos de combinaciones de tan solo dos asociaciones significativas. Estas combinaciones pueden ser "homogéneas" si comparten el mismo tipo de modalidad de dispersión o "heterogéneas" si difieren entre sí. Sin embargo, dentro de este abanico de posibilidades debe distinguirse entre la interconexión espacial de dos asociaciones -que indican los distintos tipos de configuración- y la interrelación de restos -mar-

(2) Definiendo, en este caso, cada asociación significativa como el conjunto de densidad que se compone de los restos pertenecientes a un mismo individuo. cada por la presencia de huesos de asociaciones distintas en la zona en donde tiene lugar el contacto entre ambas-. En el primer caso podría hablarse de una configuración y modalidades de dispersión determinadas, con ausencia de intersecciones, y en segunda instancia, con existencia de las mismas.

En los lugares de predación en serie las configuraciones más frecuentes son las de tipo $1 \mathrm{y}$, en los casos de solapamiento de asociaciones significativas, las de tipo 2 y, más excepcionalmente, del 4 -aunque sólo he documentado un caso de este tipo de configuración, es probable que procesos de aprovechamiento posteriores pudieran desbaratarla (Domínguez-Rodrigo, 1993)- (Fig. 7). En los lugares de muerte en masa, aunque aún no se ha aplicado este tipo de análisis, los estudios realizados por Haynes (1988b) sugieren que el tipo de configuración más frecuente es el 1 , con probabilidad de que el 2 y el 3 aparezcan de manera más esporádica.

Dada las escasas ocasiones en que las deposiciones naturales debidas a acciones cinegéticas o de muerte natural, a lugares de predación en serie o muerte en masa -salvo que sea un evento sincrónico- propician la acumulación de varios individuos en una porción muy reducida de terreno, el criterio más apropiado para distinguir deposiciones a nivel espacial es la delimitación de asociaciones significativas. Sin embargo, en el caso hipotético de que éstas resulten difíciles de discernir, por encontrarse en una acumulación relevante -como es el caso de las concentraciones generadas por transporte sistemáticoen un área reducida, el siguiente paso que debe

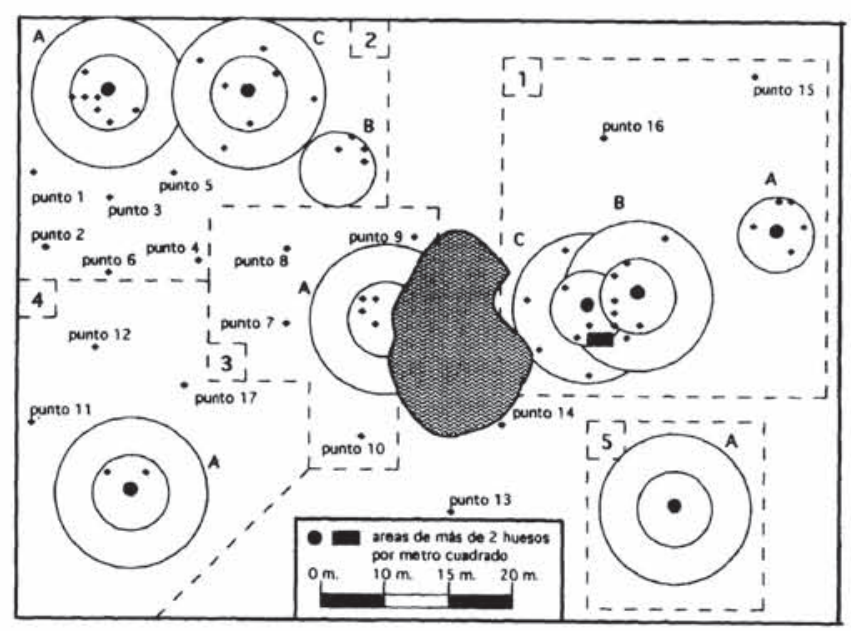

FIG. 7. Configuración de áreas y asociaciones significativas en un lugar de predación en serie: la charca de los leones (Domínguez-Rodrigo, 1993). 
darse es la aplicación de análisis espaciales basados en "conjuntos de relación". Este tipo de análisis, que relega el criterio de densidad a un plano secundario, se basa en la detección espacial de determinados atributos. Los atributos que sirven para distinguir conjuntos son el taxonómico, el anatómico, el de estado de exposición subaérea y el de marcas de dientes o patrones de alteración. El atributo taxonómico sirve para detectar la distribución espacial de cada taxón depositado y el anatómico, para observar áreas de deposición/dispersión preferenciales. Las mayores áreas de densidad involucran a huesos esencialmente axiales, mientras que las zonas de dispersión periféricas suelen mostrar especímenes óseos de carácter apendicular. El atributo de exposición subaérea sirve para aproximarse al registro con la pretensión de discernir momentos de deposición y poder otorgarles un carácter temporal.

Normalmente, el establecimiento de estos conjuntos de relación debe realizarse utilizando varios atributos al mismo tiempo. Puesto que los accesos primarios a los restos dejan una impronta espacial más fácil de detectar, el estudio de las alteraciones experimentadas por un conjunto óseo, debido a una intervención secundaria, debe hacerse empleando simultáneamente varios de estos criterios mencionados, que igualmente sirven para evaluar la dinámica deposicional y poder relacionar restos que se encuentran espacialmente separados.

Los experimentos realizados sobre los procesos de alteración de conjuntos antrópicos por una intervención secundaria de hiénidos han puesto de relieve que éstos alteran el porcentaje de representación anatómica generado por la deposición original, consumiendo elementos axiales y sesgando la representación de las epífisis (o fragmentos epifisarios) a favor de las diáfisis.. (o fragmentos diafisarios) (Marean et alii, 1992; Blumenschine \& Marean, 1993). También se ha observado que en dicho acto, las hienas dejan marcas de dientes -en un índice medio raramente superior al $20 \%$ (Blumenschine, 1988)-, en fragmentos metadiafisarios o epifisarios, cuando actúan sobre huesos largos fracturados por acción antrópica, no prestando atención a los fragmentos diafisarios (Blumenschine, 1988; Marean et alii, 1992). La conjunción de estos criterios con el análisis espacial de los mismos es sumamente revelador, ya que no sólo se descubren dichos procesos, sino que se discierne la dinámica que se esconde tras ellos. Según la dispersión espacial de estos atributos se puede inferir la intervención, por ejemplo, de una o dos hienas -que suelen realizar un consumo sin movilización significativa de restos- o de un grupo mayor -cuya competencia interna genera una mayor dispersión de huesos-.

Existe, por consiguiente, una curiosa relación entre los patrones de alteración ósea realizados por determinados agentes carnívoros y los patrones de dispersión de huesos (Fig. 8). El ejemplo que voy a poner es el del efecto de dispersión de las presas de tamaño medio-grande (ñu, cebra y búfalo) debidas a actos de predación realizados por leones y la consiguiente alteración secundaria llevada a cabo por hienas y chacales.

Distribución 1 (D1).- Ocurre cuando dentro de la zona concedida a una asociación significativa, la totalidad de huesos de una carcasa se encuentran en el área A. Dos son las causas que propician este tipo de distribución: muerte natural del animal o su captura por parte de los leones y su posterior consumo mediante un proceso AM. En este caso, para distinguir una u otra causa sería preciso acudir al criterio de patrones de alteración, como son las improntas de dientes. Si los leones capturaron al animal en época de abundancia y consumieron sólo una parte del mismo, probablemente no alteraron ningún hueso, con lo que resulta indistinguible del otro proceso natural. Pero si al consumirlo, como resulta más frecuente, lo alteraron levemente- seccionando costillas y apófisis vertebrales- esta evidencia sirve para distinguir entre ambos factores (Fig. 8).

En este tipo de distribución he observado dos variantes, creadas por la intervención secundaria de carroñeros. La primera de ellas (D1a) consiste en la alteración realizada por chacales -que pueden llevarse algún hueso apendicular fuera del área $\mathrm{C}$ - $\mathrm{y}$ hienas solitarias o en parejas. En este caso, algunos huesos se dispersan al área $\mathrm{B}$ de manera radial. Si la carcasa está articulada, estos huesos suelen ser de la sección apendicular, y si no, puede ser de cualquier tipo. La otra variante (D1b) consiste en la intervención de varias hienas. En este caso, los restos suelen alcanzar el área $\mathrm{C}$ e incluso llevarse a la zona de dispersión externa. Para esta cuestión los criterios diagnósticos son el de representación anatómica y el de patrones de alteración ósea (Fig. 8). 


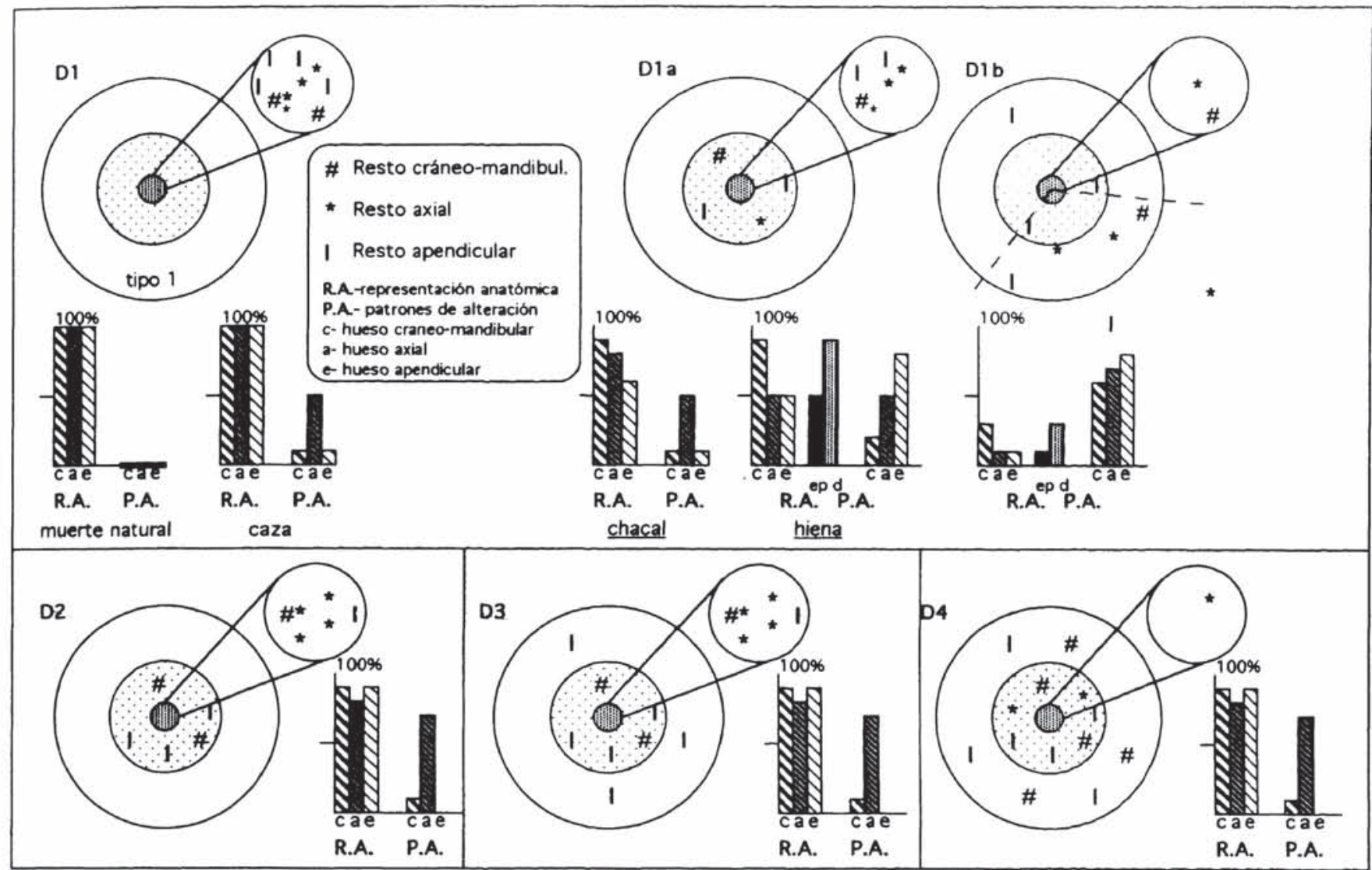

FıG. 8. Modalidades de dispersión espacial de restos por muerte natural (D1) o por predación de leones (D2, D3, y D4) y establecimiento de conjuntos de relación basados en la representación anatómica y en los patrones de alteración (fracturas y marcas de dientes). Actos de deposición primaria (D1, D2, D3 y D4) y alteración postdeposicional o de intervención secundaria (D1a y D1b). Clave: hueso cráneo-mandibular (c), hueso axial (a), hueso apendicular (e), epífisis (ep.) y diáfisis (d).

Distribución 2 (D2).- Ocurre cuando tras un acceso primario a la carcasa, la totalidad de los huesos se distribuyen en las áreas A y B. Los huesos que acceden al área $\mathrm{B}$ suelen pertenecer a las extremidades, aunque a veces también pueden pertenecer al cráneo y mandíbula. Se debe a la caza de una presa por parte de leones y a un proceso Af. Esta distribución se distinguiría de la D1a mediante el criterio de patrones de alteración -costillas y vértebras sufren una gran modificación-, para distinguirlo del creado por los chacales y, además, el criterio de representación anatómica, para diferenciarlo del generado por las hienas (Fig. 8).

Distribución 3 (D3).- Ocurre cuando tras un acceso primario a la carcasa, los huesos se distribuyen en las áreas A, B y C. Idem a D2 (Fig. 8).

Distribución 4 (D4)- Ocurre cuando tras un acceso primario a la carcasa, los huesos se distribuyen de manera que el área A se despeja -casi queda ausente de restos- y éstos aparecen dispersos por las áreas B y C, indistintamente de su carácter. También se diferencia de las variantes D1a y D1b por los criterios de representación anatómica y de alteración ósea (Fig. 8).

No obstante, en un proceso de acceso secundario -intervención de hienas y/o chacales- estas tres modalidades de distribución (D2, D3 y D4) pueden ofrecer variantes, según el alcance de dicho proceso. La primera variante (D2a, D3a y D4a) consiste en una dinámica de alteración acompañada de escasa dispersión. En este caso es detectable mediante conjuntos de relación basados en atributos de representación anatómica y patrones de alteración (Fig. 9). La segunda variante (D2b, D3b y D4b) supone un proceso de alteración más fuerte e implica la dispersión de restos dentro de las áreas $\mathrm{B}$ y $\mathrm{C}$-de modo sectorial, si se trata de hienas (Domínguez-Rodrigo, 1993)-. En este caso, el establecimiento de conjuntos de relación basados en los mismos atri- 


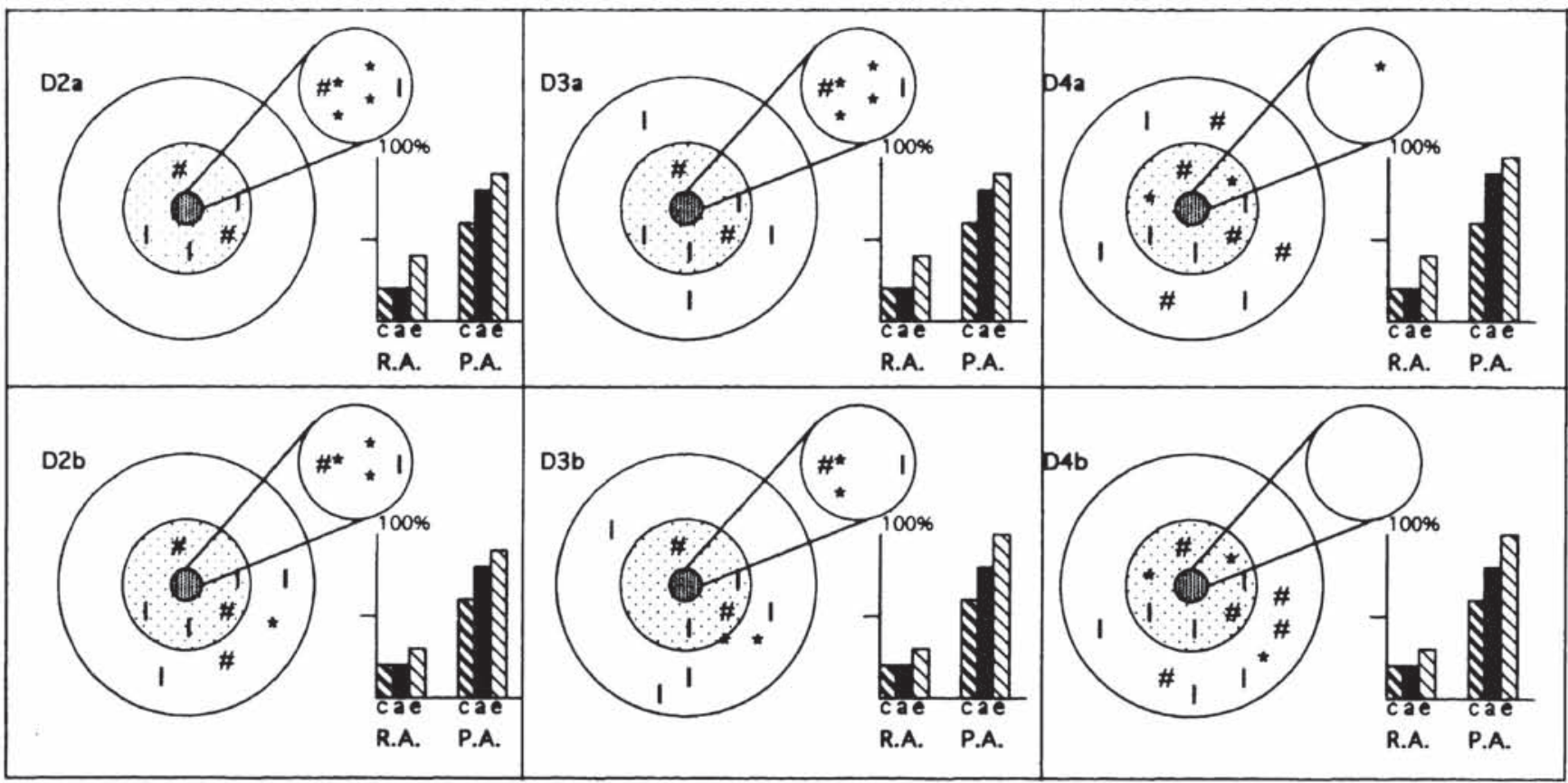

FIG. 9. Modalidades de dispersión espacial de restos por intervención inicial de leones e intervención secundaria de carroñeros y establecimiento de conjuntos de relación basados en la representación anatómica y en los patrones de alteración (fracturas y marcas de dientes). Se muestran los modelos de escasa dispersión postdeposicional (D2a, D3a y D4a) y de dispersión postdeposicional más acusada (D2b, D3b y D4b). Clave: hueso cráneo-mandibular (c), hueso axial (a), hueso apendicular (e), epífisis (ep.) y diáfisis (d).

butos que la variante anterior es igual de válido (Fig. 9). Una tercera variante (D2c, D3c y D4c) consiste en el mismo tipo de dispersión que la variante anterior, pero con traslado de huesos fuera del área $\mathrm{C}$ a diversas distancias.

\section{VALORACIÓN Y SUGERENCIAS}

La investigación etoarqueológica nos ha provisto en los últimos años de marcos referenciales, en su mayor parte orientados a los procesos de actuación primaria de los predadores -enfoque carnivorocentrista- para compensar los enfoques antropocéntricos, continuamente enriquecidos por las contribuciones realizadas desde la Etnoarqueología. Sin embargo, aún resta bastante por hacer. La disposición de marcos referenciales plurales que permitan concatenar procesos de intervención sucesivos es uno de los pasos que debe darse. A este respecto, los trabajos de Blumenschine y Marean (1993) han supuesto una serie de aportaciones de extrema calidad, en el caso de los hiénidos. Sin embargo, experimentación similar podría y debería llevarse a cabo con otros grupos de carní- voros, entre los que destacaría a los cánidos. La falta de investigación etoarqueológica de estos carnívoros supone un vacío referencial en el proceso interpretativo tafonómico de suma gravedad, por cuanto estos animales pudieron haber participado de manera significativa en la modificación y formación de los palimpsestos pleistocénicos europeos.

Gracias al trabajo realizado por algunos investigadores durante los últimos años, la mayor parte de ellos procedentes del campo arqueológico, somos capaces de comprender mejor en la actualidad algunos de los procesos causantes de determinadas alteraciones óseas diagnósticas, de gran valor para nuestros intereses tafonómicos. Además, poseemos un mejor conocimiento del comportamiento subsistencial de ciertos animales carnívoros, responsables en primera instancia de dichas alteraciones, y de sus causas. Es de esperar que futuras aportaciones rellenen los vacíos que aún afectan a esta disciplina y que puedan realizar interesantes adelantos que mejoren el marco referencial al cual la Tafonomía tiene y tendrá que hacer alusión constante. 


\section{BIBLIOGRAFÍA}

Ammann, K. \& Ammann, C. (1989): "The hunters and the hunted". Camerapix Publishers International. Nairobi.

BINFORD, L. (1981): "Bones: ancient men and modern myths". Academic Press. Nueva York.

BlumensChine, R. J. (1986): “Early hominid scavenging opportunities”. B.A.R. International Series, 283. Oxford.

- (1988): “An experimental model of the timing of hominid and carnivore influence on archaeological bone assemblages". Journal of Archaeological Science, 15: 483-502.

- (1989): "A landscape taphonomic model of the scale of prehistoric scavenging opportunities". Journal of $\mathrm{Hu}$ man Evolution, 18: 345-71.

Blumenschine, R. J. \& Marean, C. W. (1993): “A carnivore's view of archaeological bone assemblages". En J. Hudson (ed.): "From bones to Behavior: Ethnoarchaeological and experimental contributions to the interpretation of faunal remains". Center for Archaeological Investigations, Southern Illinois University. Illinois: 273-300.

BrAIN, C. K. (1981): “The hunters or the hunted?”. University of Chicago Press. Chicago.

BunN, H. T. (1982): "Meat-eating and human evolution: studies on the diet and subsistence patterns of pliopleistocene hominids in East Africa". Ph. D. thesis. Universidad de California, Berkeley.

Capaldo, S. D. (1990): "Differential treatment of axial and apendicular elements by scavenging carnivores at simulated archaeologicites". Comunicación presentada en la Biennial Conference of the Society for Africanist Archaeologists, Gainesville. Universidad de Florida, Florida.

Cavallo, J. A. (1993): “Through field glassess darkly: A naturalistic reassessment of FLK Zinjanthropus as an early hominid Living site or Central place". Four Million Years of Hominid Evolution in Africa. Congreso Internacional en honor de la contribución de $\mathbf{M}$. D. Leakey a la Paleoantropología. Arusha, Tanzania. Universidad de Dar-es-Salaam.

Cavallo, J. A. \& Blumenschine, R. J. (1989): "Tree-stored leopard kills: expanding the hominid scavenging niche". Journal of Human Evolution, 18: 393-99.

DomfNguez-Rodrigo, M. (1993): "La analítica espacial micro como herramienta tafonómica: aplicación al en- torno de una charca africana". 4" Coloquio Internacional de Arqueologia Espacial (Procesos postdeposicionales). Teruel.

- (en prensa)a: "Las razones adaptativas del comportamiento subsistencial de los animales carnívoros y sus estrategias iniciales de consumo de presas: relevancia en el proceder tafonómico". Quaderns de Prehistoria i Arqueología de Castelló.

- (en prensa)b: "Las acumulaciones óseas de macrofauna: revisión de los criterios de discernimiento de los agentes biológicos no antrópicos desde un enfoque ecológico". Zephyrus.

Fox, M. W. (1975): “The Wild Canids: Their Systematics, Behavioral Ecology and Evolution". Van Nostrand Reinhold. Nueva York.

Frame, G. (1981): "Swift and Enduring: Cheetahs and Wild Dogs of the Serengeti". Dutton. Nueva York.

HAl.TENORTH, T. \& Dil.1.er, H. (1980): “A field guide to the mammals of Africa". Collins. Londres.

HAYNES, G. (1988)a: "Mass death and serial predation: comparative taphonomic studies of modern large mammal death sites". Journal of Archaeological Science, 15: 219-35.

- (1988)b: "Longitudinal studies of african elephant death and bone deposits". Journal of Archaeological Science, 15: 131-57.

KruUk, H. \& TURNER, M. (1967): "Comparative notes on predation by lion, leopard, cheetah and wild dogs in the Serengeti area, East Africa". Mammalia, 31: 1-27.

Marean, C. W.; Spencer, M. L.; Blumenschine, R. J. \& Capaldo, S. D. (1992): "Captive hyaena bone choice and destruction, the Schlepp effect, and Olduvai archaeofaunas". Journal of Archaeological Science, 19: 101-121.

Scotr, J. (1991): "Painted wolves: wild dogs of the Serengeti-Mara". Hamish Hamilton. Londres.

SEPT, J. (1992): "Was there no place like home?". Current Anthropology, 33: 187-207.

Toth, N. \& Schick, K. (1993): "New views of the Old Stone Age: studies of Early Stone Age technology and site patterning in East Africa". Four Million Years of Hominid Evolution in Africa. Congreso Internacional en honor de la contribución de M. D. Leakey a la Paleoantropología. Arusha, Tanzania. Universidad de Dar-es-Salaam. 